\title{
Variáveis físico-geográficas e as implicações sobre vulnerabilidade ambiental na sub-bacia do Rio Guamá, Pará, Brasil
}

\begin{abstract}
A rede hidrográfica do rio Guamá é um sistema hidrológico bastante complexo em razão da inter-relação entre ambientes rurais e urbanos que sofrem influência antrópica em diferentes graus, principalmente em raz̃o de atividades econômicas. Nesse contexto, o objetivo do presente trabalho foi diagnosticar o uso e ocupação do solo, morfometria e a precipitação pluvia na área da sub-bacia do rio Guamá (nordeste paraense). Em seguida, com bases nas informações de variáveis físico-geográficas selecionadas estabelecer um diagnóstico sobre a na área da sub-bacia do rio Guamá (nordeste paraense). Em seguida, com bases nas informações de variáveis físico-geográficas selecionadas estabelecer um diagnóstico sobre a
vulnerabilidade ambiental. Foram usados processos de sensoriamento remoto e dados secundários para o estudo morfométrico (Shuttle Radar Topography Mission-SRTM), uso e ocupação da terra (imagens do satélite Sino-Brasileiro de Recursos Terrestres CBERS-4 - China-Brazil Earth Resources Satellite) e precipitação para os anos de 2015 a 2017 (CHIRPS - Climate Hazards group Infrared Precipitations with Stations). Para o estudo da distribuição cartográfica da vulnerabilidade ambiental foi aplicado o cruzamento de mapas base de geologia, tipo de solo, relevo, tipo de cobertura vegetal, clima e uso e ocupação da terra através da operação de álgebra de mapas e considerando-se o princípio de análise ecodinâmica. A área de estudo apresentou características físicas desfavoráveis ao abastecimento hídrico por localiza-se em altitude baixa e não ser bem drenada. Contudo, as características do relevo sugerem o favorecimento de baixo escoamento da água e baixa susceptibilidade à erosão e alagamentos. Em relação a quantidade de chuva foram registados elevados valores de precipitação (média anual mínima de $2.295 \mathrm{~mm}$ e máxima de $2.729 \mathrm{~mm}$ ) que não se distribuem igualmente ao longo do ano e demonstram concordância com o comportamento esperado para a região (período chuvoso entre os meses dezembro e maio e período menos chuvoso entre os meses de junho a novembro). Notou-se maior porcentagem (aproximadamente $57 \%$ ) de área classificada como solo exposto e vegetação rasteira do que área classificada como vegetação densa ou secundária (aproximadamente $42 \%$ ). A redução e a ausência de cobertura vegetal primária em alguns trechos da área vegetação rasteira do que área classificada como vegetação densa ou secundária (aproximadamente $42 \%$ ). A redução e a ausência de cobertura vegetal primária em alguns trechos da área de estudo foram evidenciadas e demonstra-se a importância do monitoramento deste tipo de cobertura para a região. Na sub-bacia do rio Guamá as áreas de baixa, média e alta
vulnerabilidade apresentaram as maiores porcentagens de ocorrência (aproximadamente $28 \%, 29 \%$ e $26 \%$, respectivamente); e, representam áreas com constante ação de processos pedogênicos e morfogênicos. Desta forma, ressalta-se a importância do controle da expansão das atividades antrópicas, retirada da vegetação primária e respeito aos preceitos legais da legislação ambiental brasileira.
\end{abstract}

\section{Physical-geographical variables and the implications on environmental vulnerability in the Guamá River sub-basin, Pará, Brazil}

\begin{abstract}
The hydrographic network of the Guamá River is a very complex hydrological system due to the interrelationship between rural and urban environments that suffer anthropic influence in different degrees, mainly due to economic activities. In this context, the objective of the present study was to diagnose the use and occupation of the soil, morphometry and rainfall in the area of the sub-basin of the Guamá River (northeastern Pará). Then, based on the information of selected physical and geographic variables, establish a diagnosis of environmental vulnerability. Remote sensing processes and secondary data were used for the morphometric study (Shuttle Radar Topography Mission - SRTM), land use and occupation (images from the vulnerability. Remote sensing processes and secondary data were used for the morphometric study (Shuttle Radar Topography Mission - SRTM), land use and occupation (images from the
Sino-Brazilian Earth Resources satellite CBERS-4 - China-Brazil Earth Resources Satellite) and precipitation for the years 2015 to 2017 (CHIRPS - Climate Hazards group Infrared Precipitations with Stations). For the study of the cartographic distribution of environmental vulnerability, the crossing of base maps of geology, type of soil, relief, type of vegetation cover, climate and land use and occupation was applied through the operation of map algebra and considering the principle ecodynamic analysis. The study area showed physical characteristics unfavorable to water supply because it is located at low altitude and is not well drained. However, the characteristics of the relief suggest the favor of low water flow and low susceptibility to erosion and flooding. Regarding the amount of rain, high precipitation values were recorded (minimum annual average of 2,295 $\mathrm{mm}$ and maximum of 2,729 mm), which are not distributed equally throughout the year and demonstrate agreement with the expected behavior for the region (rainy period between months December and May and the least rainy period between June and November). A higher percentage (approximately 57\%) of an area classified as exposed soil and undergrowth was noted than an area classified as dense or secondary vegetation (approximately $42 \%$ ). The reduction and the absence of primary vegetation cover in some sections of the study area were evidenced and the importance of monitoring this type of coverage for the region is demonstrated. In the Guamá River sub-basin, low, medium and high vulnerability areas had the highest occurrence percentages (approximately $28 \%, 29 \%$ and $26 \%$, respectively); and, they represent areas with constant action of pedogenic and morphogenic processes. Thus, the importance of controlling the expansion of human activities, removing primary vegetation and respecting the legal precepts of Brazilian environmental legislation is emphasized.
\end{abstract}

Keywords: Geographic Information Systems (GIS); Northeastern paraense; Geoprocessing; Morphometric compartmentation; Use and land cover.

Topic: Desenvolvimento, Sustentabilidade e Meio Ambiente

Reviewed anonymously in the process of blind peer.
Received: 11/03/2020

Approved: 19/04/2020
Ivan Carlos da Costa Barbosa (iD)

Universidade Federal Rural da Amazônia, Brasil

http://lattes.cnpq.br/3888979612130966

http://orcid.org/0000-0002-7358-5789

ivan.barbosa1212@gmail.com

Adriano Marlisom Leão de Sousa (iD

Universidade Federal Rural da Amazônia, Brasil

http://lattes.cnpq.br/4371199443425884

http://orcid.org/0000-0002-2809-5318

marlisoms@yahoo.com.br

Emerson Renato Maciel da Silva (iD

Universidade Federal do Pará, Brasil

http://lattes.cnpq.br/5581525631767986

http://orcid.org/0000-0001-8643-0826

emersonrvs255@gmail.com

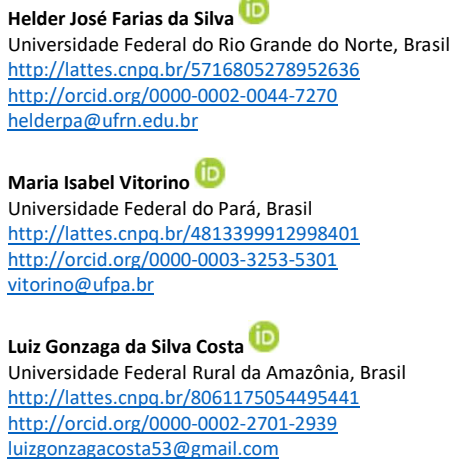

Referencing this:

BARBOSA, I. C. C.; SOUZA, A. M. L.; SILVA, E. R. M.; SILVA, H. J. F.; VITORINO, M. I.; COSTA, L. G. S.. Variáveis físico-geográficas e as implicações sobre vulnerabilidade ambiental na sub-bacia do Rio Guamá, Pará, Brasil. Revista Ibero Americana de Ciências Ambientais, v.11, n.3, p.264-291, 2020. DOI: http://doi.org/10.6008/CBPC2179$\underline{6858.2020 .003 .0022}$
DOI: 10.6008/CBPC2179-6858.2020.003.0022 


\section{INTRODUÇÃO}

O entendimento de bacia hidrográfica reconhece-a como um sistema interligado e que a subdivisão de grandes bacias em bacias menores (sub-bacias) facilita o diagnóstico e o monitoramento ambiental, correlações entre qualidade da água e a dinâmica de uso e ocupação da terra, delimitação de áreas críticas, identificação de processos impactantes entre outros estudos (MORAES et al., 2016). Assim, uma série de informações é necessária para o manejo adequado dos recursos hídricos inseridos em um contexto dinâmico de funcionamento destes sistemas em uma bacia ou sub-bacia hidrográfica (LOPES et al., 2014).

Uma destas informações corresponde à análise morfométrica que representa um excelente instrumento de análise da dinâmica e da sensibilidade da bacia (ou sub-bacia) à deterioração ambiental, pois parâmetros morfométricos são obtidos a partir de dados físicos do local e possuem uma alta correção com a morfologia, clima e pedoforma (FRANCO et al., 2016). De acordo com Lima (1976) e Santos et al. (2020), o comportamento hidrológico de uma bacia (ou sub-bacia) hidrográfica é função de suas características geomorfológicas (forma, relevo, área, geologia, rede de drenagem, solo, etc.) e do tipo de cobertura vegetal existente.

A precipitação dificilmente segue um padrão físico idêntico (MARCIANO et al., 2018) e também representa uma excelente fonte de informações. De acordo com Amanajás et al. (2012), em regiões tropicais, como a Amazônia, a precipitação apresenta-se como uma informação fortemente ligada ao planejamento das atividades do homem e ao desenvolvimento local. Os autores citam ainda a importância da regularidade e distribuição espacial desta variável climatológica como fatores limitantes ao desenvolvimento das atividades agrícolas na região e ao manejo dos recursos naturais.

Silva et al. (2016) e Gutierrez et al. (2017) relatam as modificações sofridas pelas paisagens decorrentes das alterações de uso e ocupação da terra ocasionadas pelo homem. Nota-se que neste cenário de transformações que os vários tipos de usos da terra, que antes eram ocupadas por vegetação, vão convertendo paisagens naturais em extensas áreas antropizadas (PONTE et al., 2016; GUTIERREZ et al., 2017). Contudo, verifica-se a existência de uma distinção entre os tipos, a magnitude e a periodicidade das atividades antrópicas em diferentes bacias (ou sub-bacias) hidrográficas. O que ocasiona uma dificuldade em estabelecer generalizações (ANA, 2011) na descrição das características e potencialidades de cada localidade (SOUZA et al., 2017).

A rede hidrográfica do rio Guamá é um sistema hidrológico bastante complexo em razão da interrelação entre ambientes rurais e urbanos que sofrem influência antrópica em diferentes graus, principalmente em razão de atividades econômicas (IDESP, 2014). A Bacia Hidrográfica do Rio Guamá e Outros (BHRGO) é formada por um sistema de drenagem onde quatro rios se juntam. Cada um destes quatro rios compõe uma sub-bacia dentro da BHRGO, ou seja, as sub-bacias do rio Guamá (SBRG), rio Capim (SBRC), rio Acará (SBRA) e rio Moju (SBRM) formam, a partir de sua confluência, um único sistema de drenagem possuindo como exutório a baía do Guajará, em frente à cidade de Belém (capital do estado do Pará). Entretanto, verifica-se que nos últimos anos muitos estudos (BRAUN et al., 2008; FUJIMOTO et al., 2020; 
ARAÚJO et al., 2011; MELO et al., 2012; RODRIGUES et al., 2018; ABREU et al., 2007) relacionando aspectos hidrológicos, climáticos, biológicos, químicos, físico-químicos, entre outros foram concentrados em trechos da BHRGO localizados nas proximidades de seu exutório, às margens da capital do estado paraense, ou em pequenos trechos ao longo da bacia hidrográfica.

Dentre as quatro sub-bacia citadas, a sub-bacia do rio Guamá (SBRG) apresenta grande representatividade para a região (BARROS et al., 2012), devido ao uso da terra, crescimento econômico, expansão das atividades agropecuárias, propriedades físico-bióticas, características socioeconômicas, uso da água, etc. Assim, entende-se necessária uma ferramenta que promova uma abordagem integrada entre os aspectos antrópicos (uso e ocupação da terra) e os aspectos naturais (clima, relevo, solo, geologia, morfometria, etc.) de uma determinada área. Moreira et al. (2015) destacam os efeitos negativos na produção de água devido aspectos relacionados ao uso da terra, tipo de vegetação e as atividades antrópicas. O mapa de vulnerabilidade ambiental pode ser considerado uma ferramenta, com base no emprego do Sistema de Informação Geográfica (SIG) (MANZANO et al., 2019), voltada para estudos de cunho ambiental (COSTA et al., 2006); e que está vulnerabilidade ambiental será formada por um grupo de fatores ambientais (naturais e antrópicos presentes ou futuros) que poderão afetar, parcial ou integralmente, a estabilidade ecológica de uma região (ANDERSEN et al., 1989). Segundo Tagliani (2003), a vulnerabilidade ambiental de uma área está relacionada a sua maior ou menor susceptibilidade a um potencial impacto decorrente de qualquer tipo de uso antrópico; ou seja, o mapa de vulnerabilidade ambiental tem como principal finalidade fornece uma representação de todo conhecimento no tempo presente das respostas dadas aos processos de uso do solo de uma determinada área (COSTA et al., 2006). Um sistema é mais vulnerável à medida que forem maiores as pressões e a sua sensibilidade, e menor sua capacidade de adaptação (MILANEZI et al., 2016).

Desta forma, o objetivo do presente trabalho foi diagnosticar o uso e ocupação solo, a morfometria e a precipitação pluvial (entre os anos de 2015 e 2017) na área da sub-bacia do rio Guamá, localizada no nordeste do Estado do Pará. Em seguida, com bases nas informações de variáveis físico-geográficas selecionadas (declividade, precipitação pluvial, tipo de solo, geologia, tipo de cobertura vegetal e uso e ocupação) estabelecer, por meio de técnicas de geoprocessamento em um SIG, as implicações sobre a vulnerabilidade ambiental.

\section{MATERIAIS E MÉTODOS}

\section{Área de Estudo}

A modulação da bacia hidrográfica do rio Guamá e outros (BHRGO) está representada na Figura 1a. Os afluentes mais importantes estão na margem esquerda e são os rios Capim, Acará e Moju. O rio Guamá pode ser dividido em dois trechos onde a divisão ocorre no trecho em que o rio Capim deságua no rio Guamá na altura da cidade de São Domingos do Capim e juntos desaguam na foz localizada na baía do Guajará em Belém (Pará). Este trecho não será objeto de estudo desta pesquisa. A BHRGO está localizada na região 
nordeste do Estado do Pará, situada entre as coordenadas $1^{\circ} 30^{\prime} 00^{\prime \prime}$ e $2^{\circ} 30^{\prime} 00^{\prime \prime}$ de latitude Sul e $49^{\circ} 00^{\prime} 00^{\prime \prime}$ e $46^{\circ} 30^{\prime} 00^{\prime \prime}$ de longitude Oeste. Ainda de acordo com Figura 1a é possível observar toda a extensão do rio Guamá correspondente a 380,72 km.

A área de estudo deste trabalho (Figura 1b) compreende a sub-bacia do rio Guamá (SBRG) que se inicia nas matas dos municípios de Ipixuna e Nova Esperança do Piriá (acima de Paragominas), seguindo por Capitão Poço e Garrafão do Norte, a sudoeste, e finalmente dirigindo-se para norte-nordeste até o município de Ourém. Deste ponto em diante o rio flete para oeste, divisando São Miguel do Guamá de outros três municípios. Os municípios que abrangem a SBRG são: Aurora do Pará, Bonito, Capitão Poço, Garrafão do Norte, Ipixuna do Pará, Irituia, Mãe do Rio, Nova Esperança do Piriá, Ourém, Santa Luzia do Pará, São Domingos do Capim e São Miguel do Guamá, localizados na mesorregião do nordeste paraense e microrregião do Guamá. Esta porção da bacia não sofre a influência do rio Capim que representa um curdo d'água de grande extensão e volume. Logo, o trecho em estudo tem como rio principal apenas o rio Guamá. A área da sub-bacia do rio Guamá (SBRG) corresponde a 65,69\% da área total da bacia hidrográfica do rio Guamá e outros (BHRGO).

Na Figura 1b é possível a rede de drenagem do rio principal e a localização de algumas comunidades às margens do rio Guamá (pontos circulares em vermelho). A sub-bacia hidrográfica do rio Guamá (SBRG) está localizada na Mesorregião do Nordeste Paraense (formada por 49 municípios) e na microrregião do

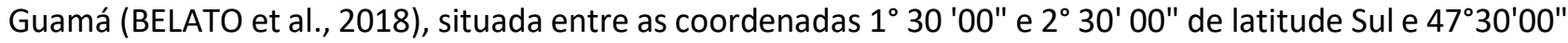
e $47^{\circ} 00^{\prime} 00^{\prime \prime}$ de longitude Oeste. Neste trecho é possível destacar que o rio principal possui uma extensão de $281,50 \mathrm{~km}$.
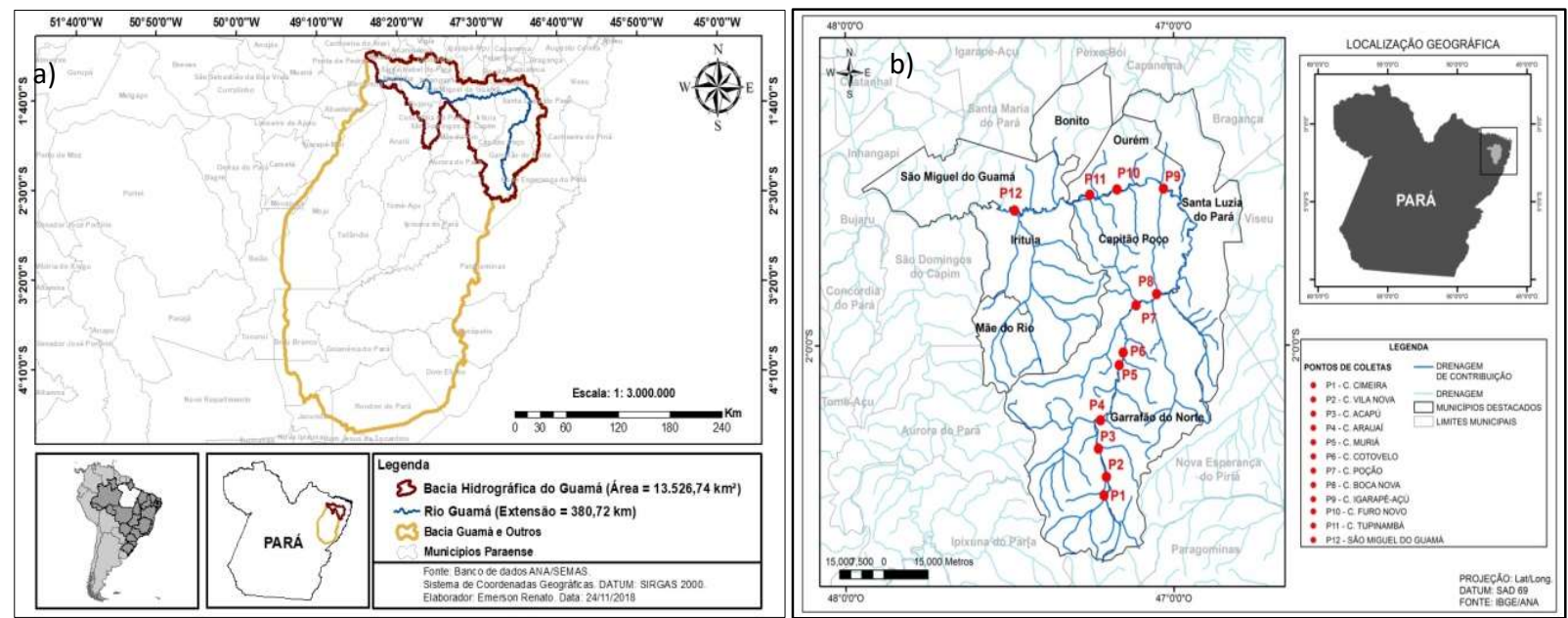

Figura 1: (a) Dimensão espacial da bacia hidrográfica do rio Guamá e outros (BHRGO) e da área em estudo: sub-bacia do rio Guamá (SBRG); (b) Distribuição dos pontos amostrais na área em estudo.

A classificação de Köppen para o clima da região é do tipo megatérmico Af possuindo um clima quente tropical úmido, com chuvas em todas as estações, temperatura média anual entre 24 e $26^{\circ} \mathrm{C}$ (NIMER, 1989; FISCH et al., 1998). A precipitação apresenta grande variabilidade espaço-temporal ao longo do ano (AMANAJÁS et al., 2012) podendo ser identificados dois períodos distintos: um chuvoso com elevada precipitação e diretamente influenciado pela migração sazonal da Zona de Convergência Intertropical (ZTIC) 
na direção meridional; e outro menos chuvoso, sem período de seca definido (FISCH et al., 1998; SOUZA et al., 2003).

São encontrados na área da SBRG, a partir da base de dados do Instituto Brasileiro de Geografia e Estatística (IBGE) na escala de 1:250.000, cinco classes de solos, distribuídos da seguinte forma: 82\% Latossolo Amarelo, 5\% de Neossolo Quartzarcnico, 4\% de Argilossolo Vermelho-amarelo, 8\% de Gleissolo Háplico e 1\% de Massa D’Água.

\section{Dados Morfométricos}

Para realização desse trabalho foi utilizado o software QuantumGIS versão 3.4 (software gratuito) e algumas de suas diversas ferramentas. Além do software Global Mapper que foi utilizado no georreferenciamento de algumas imagens. Inicialmente, delimitou-se a sub-bacia do rio Guamá, e seus tributários para preparação da análise morfométrica. Desta forma, elaborou-se primeiramente o mapa de drenagem partir dos dados georreferenciados do relevo, ou seja, foi produzido um modelo digital de elevação (MDE) com a rede hidrográfica.

A delimitação da SBRG foi realizada a partir dos dados georreferenciados do relevo da área, os quais são derivados de produtos da missão Shuttle Radar Topography Mission (SRTM, em português Missão Topográfica Radar Shuttle) com resolução espacial de 30 metros, disponibilizado de forma gratuita na base de dados da Earth Resources Observation and Science (EROS) e United States Geological Survey (USGS) (MENDES, 2018). Assim, para realizar o processamento se utilizou de determinadas extensões do software QGIS e da ferramenta TauDEM (Terrain Analysis Using Digital Elevation Models), versão 5.3, que se constitui em uma extensão gratuita que pode ser instalada no programa QGIS. Para a sub-bacia hidrográfica do rio Guamá foram utilizados os arquivos S02W048, S03W048, S02W047 e S03W047.

Tabela 1: Fórmulas utilizadas para os cálculos dos parâmetros morfométricos da sub-bacia do rio Guamá.

\begin{tabular}{|l|l|}
\hline Parâmetro & Fórmula* \\
\hline Coeficiente de compacidade (Kc) & $\mathrm{Kc}=0,28 \frac{\mathrm{P}}{\sqrt{\mathrm{A}}}$ \\
\hline Fator de forma (F) & $\mathrm{F}=\frac{\mathrm{A}}{\mathrm{L}^{2}}$ \\
\hline Índice de circularidade (IC) & $\mathrm{IC}=\frac{12,57 \times \mathrm{A}}{\mathrm{P}^{2}}$ \\
\hline Gradiente de canais (Gc) & $\mathrm{Gc}=\frac{\left(\frac{\mathrm{Amáx}}{\mathrm{L}}\right)}{10}$ \\
\hline Relação de relevo (Rr) & $\mathrm{Rr}=\frac{\mathrm{Hm}}{\mathrm{L}}$ \\
\hline Densidade de drenagem (Dd) & $\mathrm{Dd}=\frac{\mathrm{L}_{\mathrm{t}}}{\mathrm{A}}$ \\
\hline Densidade de rios ou hidrográfica (Dh) & $\mathrm{Dh}=\frac{\mathrm{N}}{\mathrm{A}}$ \\
\hline Extensão do percurso superficial (Eps) & $\mathrm{Eps}=\frac{1}{2 \mathrm{Dd}}$ \\
\hline Índice de rugosidade (Ir) & $\mathrm{Ir}=\mathrm{H}_{\mathrm{m}} \times \mathrm{Dd}$ \\
\hline
\end{tabular}

* $\mathrm{P}=$ perímetro da bacia; $\mathrm{A}=$ área de drenagem da sub-bacia; $\mathrm{L}=$ comprimento do eixo da sub-bacia. $A_{\text {máx }}=$ altitude máxima; $\mathrm{H}_{\mathrm{m}}=$ amplitude altimétrica; $\mathrm{Lt}=$ comprimento total dos rios ou canais; $\mathrm{N}$ = número total de cursos d'água.

De posse da delimitação da sub-bacia hidrográfica do rio Guamá e dos demais resultados, como o MDE, foram determinadas as características físicas da sub-bacia. Segundo Tonello (2005), as características morfométricas são divididas em características geométricas, do relevo e da rede de drenagem. As características geométricas são formadas pela forma da bacia, área total da bacia e perímetro total, 
coeficiente de compacidade (Kc), fator de forma (F), índice de circularidade (IC) e padrão de drenagem (SANTOS et al., 2017; TONELLO, 2005; CHRISTOFOLETTI, 1980). Para todos os parâmetros morfométricos calculados é possível consultar as fórmulas estão expostas na Tabela 1.

As características do relevo são formadas pela altitude mínima, altitude máxima, amplitude altimétrica, gradiente de canais $(\mathrm{Gc})$, relação de relevo ( $\mathrm{Rr}$ ) e declividade (em porcentagem) (MACHADO et al., 2011; VILLELA et al., 1975; SCHUMM, 1956; HORTON, 1945). As características da rede de drenagem são formadas pela ordenação dos canais (quantidade de canais por ordem e extensão total dos canais por ordem), comprimento do curso d'água principal; comprimento total dos cursos d'água; densidade de drenagem (Dd), densidade de rios ou hidrográfica (Dh), extensão do percurso superficial (Eps) e índice de rugosidade (Ir) (SANTOS et al., 2017; STIPP et al., 2010; PINTO JUNIOR et al., 2005; MACHADO, 2004; CHIRSTOFOLETTI, 1980; STRAHLER, 1952; HORTON, 1945).

\section{Dados do Uso e Ocupação do Solo}

Para a análise do estado atual do uso e ocupação da terra na área da sub-bacia do rio Guamá foram utilizadas informações extraídas do processo de segmentação de imagens do satélite Sino-Brasileiro de Recursos Terrestres CBERS-4 (China-Brazil Earth Resources Satellite): sensor MUX (câmera multiespectral regular - imageador de média resolução) nas bandas 8,7 e 6, respectivamente 0,77-0,89 $\mu \mathrm{m}$ (NIR), 0,52-0,59 $\mu \mathrm{m}(\mathrm{G})$ e 0,63-0,69 $\mu \mathrm{m}(\mathrm{R})$ para realização das composições coloridas falsa-cor para posterior classificação das mesmas; resolução espacial de 20 metros (imagea toda a superfície terrestre em 26 dias - dias de revisita); quantização de 8 bits; órbita /ponto 160/102, 161/102 e 160/103 todos do dia 17 de julho de 2017 (imagens selecionadas devido menor cobertura de nuvens). As informações são disponibilizadas de maneira gratuita no site $^{1}$. Destaca-se que as imagens obtidas para a área de estudo já são georreferenciadas, tradadas pela plataforma do INPE (Instituto Nacional de Pesquisas Espaciais) e disponibilizadas em formato FTP via internet.

De acordo com Freitas (2010), o satélite CBERS surgiu em 1988 a partir de uma parceria entre o Brasil e a China, no setor técnico científico espacial, no sentindo de assegurar uma regularidade no abastecimento e disponibilidade de dados orbitais de sensores remotos. O satélite CBERS-4 é o quinto produto deste programa entre os dois países e disponibiliza suas imagens de maneira gratuita para milhares de usuários para fins de uso nas áreas ambiental, agrícola e/ou planejamento urbano (SANTOS, 2014). Ainda de acordo com o autor, este satélite possui quatro câmeras de alta resolução, desloca-se a uma velocidade de 4,2 km/s e os seus quatro sensores (MUX, PAN, IRS e WFI) enviam imagens de $120 \mathrm{~km}$ a $860 \mathrm{~km}$ de extensão. Posteriormente, com as imagens obtidas foi realizada a fusão das imagens CBERS-4 para a área da sub-bacia do rio Guamá utilizando software livre QuantumGIS, versão 3.4, no Laboratório de Geoprocessamento, Análise Espacial e Monitoramento por Satélite (LAGAM) localizado na Universidade Federal Rural da Amazônia.

${ }^{1}$ http://www.dgi.inpe.br/CDSR 
A coleta de pontos de amostragem de uso e ocupação de solo foi obtida com auxílio de aparelho de GPS (Garmin, GPSMAP ${ }^{\circledR}$, série 78) e foi realizada em condição de campo na área da SBRG (Tabela 2). Durante as saídas de campo foram selecionadas doze comunidades localizadas às margens do rio Guamá (Figura 1b) para a conferência dos dados. Estas campanhas foram realizadas durante os anos de 2015 (fevereiro e junho), 2016 (janeiro e junho) e 2017 (fevereiro e junho). É importante citar que o rio Guamá é utilizado como um marcador geográfico que separa os limites territoriais dos municípios da região, por isso a dualidade da localização municipal dos pontos (Tabela 2).

Tabela 2: Pontos de coleta por comunidade.

\begin{tabular}{|c|c|c|c|c|}
\hline Ponto & Comunidade & Latitude (S) & Longitude (W) & Municípios \\
\hline 1 & Cimeira & $2 \div 24^{\prime} 30,63^{\prime \prime}$ & 470 12' 53,34" & \multirow[t]{8}{*}{ Capitão Poço/Garrafão do Norte } \\
\hline 2 & Vila Nova & $2021^{\prime} 50,52^{\prime \prime}$ & 47으 12' 7,59" & \\
\hline 3 & Acapu & $2016^{\prime} 53,18^{\prime \prime}$ & 470 13'33,37" & \\
\hline 4 & Arauaí & $2012^{\prime} 1,55^{\prime \prime}$ & 470 13'27,65" & \\
\hline 5 & Muriá & 20 3' 4,04" & 47응 38,92" & \\
\hline 6 & Cotovelo & $2 \circ 0 \prime 46,80^{\prime \prime}$ & 47으 9' 16,05" & \\
\hline 7 & Poção & $1053^{\prime} 20,78^{\prime \prime}$ & $4706^{\prime} 41,66^{\prime \prime}$ & \\
\hline 8 & Boca Nova & $1051^{\prime} 20,70^{\prime \prime}$ & $4702^{\prime} 52,93^{\prime \prime}$ & \\
\hline 9 & Igarapé-Açu & $1033^{\prime} 48,55^{\prime \prime}$ & $4701^{\prime} 55,75^{\prime \prime}$ & \multirow[t]{3}{*}{ Ourém/Capitão Poço } \\
\hline 10 & Furo Novo & 1은 $34^{\prime} 5,71^{\prime \prime}$ & 47ㅇ 10' 18,95" & \\
\hline 11 & Tupinambá & 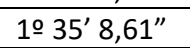 & $47015^{\prime} 4,86^{\prime \prime}$ & \\
\hline 12 & Centro urbano & $1037^{\prime} 31,56^{\prime \prime}$ & 47은 29' 5" & São Miguel do Guamá/Irituia \\
\hline
\end{tabular}

O catalogo de imagens do INPE dar informações para a correção manual da imagem, no entanto o próprio INPE disponibiliza as imagens já tratadas. Consecutivamente, foi realizada a classificação supervisionada de padrões com a utilização do plugin Dzetsaka Classification Tool baseado no classificador Gaussian Mixture Model (Modelo de Mistura Gaussiano) que apresenta bons resultados para determinar as classes Favuel et al. (2015). Segundo Batista et al. (2009), a classificação supervisionada é fundamentada em estabelecer um determinado grupo de pixels como proveniente de uma classe específica. Ressalta-se que para a classificação foi contemplado um conjunto de polígonos relativos a cada classe escolhida (um total de 280 amostras sendo 50 amostras para a classe de vegetação densa, 50 amostras para vegetação secundária, 50 amostras para vegetação rasteira, 50 amostras para solo exposto e 80 amostras para classe de corpos d'água), referente às principais classes a serem discriminadas no mapa de uso e ocupação da terra.

Depois de finalizada esta etapa, gerou-se o índice Kappa da imagem classificada para validar a precisão dos resultados da classificação supervisionada. Este índice foi calculado conforme citado por Hudson et al. (1987) e sua exatidão por Congalton et al. (1999). Os valores deste índice variam na escala de 0 e 1 , onde 0 significa que não há concordância entre a imagem classificada e a imagem de referência e 1 significa que as imagens são totalmente idênticas. Desta forma, quanto maior o índice Kappa melhor a exatidão da classificação. Segundo Landis et al. (1977), os níveis de relevância para o índice Kappa variam de: <0,00 (relevância nula); 0,02 a 0,2 (relevância ruim); 0,21 a 0,4 (relevância fraca); 0,41 a 0,6 (relevância moderada); 0,61 a 0,8 (relevância substancial); e, 0,81 a 1,00 (relevância quase perfeita).

Por fim, com as classificações geradas, os resultados foram representados na forma de mapa de uso e ocupação da terra da sub-bacia do rio Guamá. Foram determinadas as seguintes classes de uso: vegetação densa; vegetação secundária, vegetação rasteira, solo exposto e água. A elaboração final do layout dos mapas 
também foi feita no software QuantumGIS, versão 3.4.

\section{Dados de precipitação pluvial}

De acordo com Jiménez et al. (2013), a radiação eletromagnética refletida e emitida pela superfície e atmosfera do planeta é detectada por sensores presentes em satélites. A radiação eletromagnética é interpretada no espectro eletromagnético de acordo com determinados comprimentos de onda. Ainda segundo os autores, as agências administradoras destes satélites fazem o processamento dos dados brutos de radiação e disponibilizam estes dados de sensoriamento remoto em formato espacial tipo raster (pixel) em diferentes resoluções temporal e espacial.

Os dados de chuva utilizados neste trabalho foram obtidos a partir da chuva estimada por sensoriamento remoto e disponibilizada pela base de dados de precipitação de alta resolução do produto CHIRPS (Climate Hazards group Infrared Precipitations with Stations), para o período compreendido entre os anos de 2015 a 2017.

É importante destacar que o CHIRPS utiliza um algoritmo de ponderação da distância inversa no processo de tratamento dos seus dados (DUAN et al., 2016) em escala que cobre quase todo globo (entre 50ㅇ a 50N e todas as longitudes) desde 1981 até a presente data (DUAN et al., 2016). Além de fornecer um conjunto de dados de precipitação de alta resolução espacial a $0,05^{\circ} \times 0,05^{\circ}$ de resolução horizontal (cerca de $5 \mathrm{~km}$, no equador) (ESPINOZA et al., 2019; FUNK et al. 2015).

De acordo com Silva et al. (2019), a produção de dados elaborada pelo CHIRPS é formada por estações meteorológicas (convencionais e automáticas) distribuídas por mais de 27 mil pontos pelo planeta e por dados provenientes de satélites meteorológicos. Para o produto finalizado é realizada a comparação dos dados derivados das estimativas de precipitação por satélite (FUNK et al., 2015) com dados provenientes de estações de superfície. Além da combinação dos dados de estações de medição com dados de estimativas de precipitação obtidos via sistemas de satélites com alta resolução do GPCC (Global Precipitation Climatology Centre) e CRU (Climatic Research Unit).

Os dados utilizados neste trabalho foram adquiridos através do sítio eletrônico², em formato NetCDF, GeoTiff e Esri BIL. Sendo que, para a área da sub-bacia do rio Guamá foram incorporados 546 pontos de grade que foram posteriormente tratados. Para realização das análises estatísticas no conjunto de dados foi utilizado o software $R$, através da implementação das funções disponíveis nos pacotes. Desta forma, foi possível relacionar as classes de uso e ocupação do solo atuais da área de estudo, as características morfométricas e o comportamento da chuva no período compreendido entre 2015 e 2017 (período sob análise). A elaboração final do layout dos mapas também foi feita no software QuantumGIS, versão 3.4.

\section{Dados para Vulnerabilidade Ambiental}

Existe uma grande dificuldade na comparação de resultados sobre vulnerabilidade, pois não existe

\footnotetext{
${ }^{2}$ https://www.chc.ucsb.edu/data/chirps
} 
um consenso científico acerca do seu significado. Logo, a escolha dos indicadores para o estabelecimento da vulnerabilidade deve ser realizada com base no conceito adotado e no objetivo da análise (FIGUEIRÊDO et al., 2010). Com base no interesse do presente estudo foram levantadas as características físicas, bióticas e antrópicas consideradas como objeto de estudo para a vulnerabilidade ambiental na sub-bacia do rio Guamá.

Conforme Costa et al. (2006), as variáveis geologia e tipo de solo são importantes, pois estão relacionadas à morfogênese e a pedogênese. Enquanto que, o tipo de vegetação se relaciona com a estrutura das redes e teias alimentares, estágio de fitossucessão e a biodiversidade. Ainda segundo estes autores as pressões antrópicas são identificadas através das informações de uso e ocupação da terra. De acordo com Milanezi et al. (2016), a declividade está diretamente relacionada à susceptibilidade a erosão, pois quanto maior a inclinação do relevo maior os agravos. Os autores afirmam que a inclinação transforma a energia potencial em energia cinética, ocasionando elevação na velocidade das massas de água que são escoadas na superfície. O clima, representado pela precipitação mensal entre os anos de 2015 e 2017, foi adicionado devido às evidências apresentadas anteriormente da existência de diferenças na sub-bacia do rio Guamá e interferem na distribuição da chuva na área em estudo.

Quanto à obtenção destas variáveis, anteriormente foram apresentadas as formas de aquisição dos dados para as variáveis: declividade, clima e uso e ocupação da terra. Os dados de geologia e solos foram obtidos a partir dos dados do Instituto Brasileiro de Geografia e Estatística (IBGE) do projeto RADAM. Os dados obtidos para tipo de cobertura vegetal são provenientes do Projeto de Conservação e Utilização Sustentável da Diversidade Biológica Brasileira - PROBIO.

Desta forma, o mapa de vulnerabilidade ambiental foi gerado a partir do cruzamento de mapas base de geologia, tipo de solo, relevo (representado pela declividade), tipo de vegetação, clima (representado pela precipitação pluvial) e uso e ocupação da terra, para identificação da intensidade e da distribuição da vulnerabilidade na área de estudo. O conjunto das variáveis físico-geográficas selecionadas foi integrado para geração e armazenamento da base de dados georreferenciada no software QuantumGIS, versão 3.4, através da operação de álgebra de mapas. De acordo com Klais et al. (2012), a análise de informações geográficas realizada pela álgebra de mapas é formada por um conjunto de técnicas que incluem a reclassificação, a interseção (overlay) e operações matemáticas entre mapas e bancos de dados.

A integração dos dados seguiu as orientações do modelo estabelecido por Crepani et al. (2001), onde o grau de vulnerabilidade estimado para cada classe de uma determinada variável é distribuído em uma escala de 1,0 a 3,0. Segundo Tricart (1977), a escala de vulnerabilidade é realizada com base na caracterização morfodinâmica e é estipulada de acordo com critérios oriundo dos princípios da Ecodinâmica. Assim, os valores próximos a 1,0 representam situações onde predominam os processos de pedogênese (ambientes estáveis); os valores em torno de 2,0 representam situações intermediárias (ambiente de equilíbrio/intermediário); e, valores próximos a 3,0 que representam situações onde predominam os processos erosivos que modificam as formas de relevo (morfogênese) (ambientes instáveis). Sendo assim, adotou-se graus de vulnerabilidade para cada classe dentro das variáveis físico-geográficas selecionadas, conforme Crepani et al. (2001), Leite et al. (2013) e Carneiro et al. (2017). 
Após o cruzamento dos mapas anteriormente obtidos, foi calculada a média aritmética ponderada dos valores de vulnerabilidade de cada classe. Este resultado aritmético foi organizado em cinco classes de vulnerabilidade ambiental, conforme a Tabela 3.

Tabela 3: Média aritmética para as classes de vulnerabilidade ambiental.

\begin{tabular}{|c|c|c|c|}
\hline \multicolumn{3}{|l|}{ MÉDIA } & GRAU DE VULNERABILIDADE \\
\hline \multirow{5}{*}{ 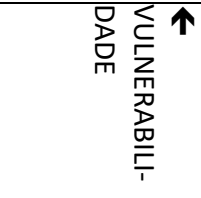 } & $2,7-3,0$ & \multirow{5}{*}{ 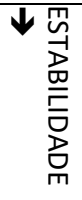 } & Muito Alta \\
\hline & $2,3-2,6$ & & Alta \\
\hline & $1,8-2,2$ & & Média \\
\hline & $1,4-1,7$ & & Baixa \\
\hline & $1,0-1,3$ & & Muito Baixa \\
\hline
\end{tabular}

Para o cálculo final da vulnerabilidade ambiental foi aplicado o método de ponderação de fatores que permitisse a flexibilidade na compensação entre os fatores do conjunto de pesos compensatórios que determinam a importância relativa de cada fator (COSTA et al., 2006). Ainda segundo Costa et al. (2006), para obtenção de um mapa de vulnerabilidade ambiental que possa demonstrar melhor as especificidades de uma determinada área em relação ao grau e tipo de antropização, é atribuído um peso maior ao fator uso e ocupação da terra em relação aos demais (Tabela 4).

Tabela 4: Pesos atribuídos a cada fator o estudo da vulnerabilidade ambiental.

\begin{tabular}{|l|l|}
\hline Fator & Peso \\
\hline Geologia & $10 \%$ ou 0,1 \\
\hline Tipo de solo & $10 \%$ ou 0,1 \\
\hline Declividade & $10 \%$ ou 0,1 \\
\hline Tipo de vegetação & $10 \%$ ou 0,1 \\
\hline Clima & $10 \%$ ou 0,1 \\
\hline Uso e ocupação da terra & $50 \%$ ou 0,5 \\
\hline
\end{tabular}

\section{RESULTADOS E DISCUSSÃO}

\section{Análise Morfométrica}

Em termos de caracterização geométrica, na Tabela 5 são apresentadas as características da subbacia hidrográfica do rio Guamá. O valor do coeficiente de compacidade (Kc) encontrado associado ao respectivo fator de forma da sub-bacia do rio Guamá indica que, em condições normais de precipitação, a SBRG é pouco suscetível a enchentes. O que pode ser corroborado pelo baixo fator de forma (F). O resultado do índice de circularidade (IC) indica um afastamento da unidade, e que sub-bacia não tende à forma circular, ou seja, possui forma mais alongada. Segundo Villela et al. (1975), a área de estudo apresenta menor concentração de deflúvio devido o afastamento da forma circular. Nota-se que a sub-bacia apresenta uma forma triangular, pois é um triângulo a figura geométrica que a cobre da melhor maneira possível. Para uma bacia ou sub-bacia, o sistema de drenagem é constituído pelo canal principal e seus canais tributários. $\mathrm{O}$ padrão de drenagem vai depender da estrutura geológica do local, tipo de solo, topografia e clima e irá influenciar no comportamento hidrológico de toda área da sub-bacia. O padrão encontrado para a sub-bacia do rio Guamá é o dendrítico e é caracterizado pelo desenvolvimento semelhante à configuração de uma árvore. Este tipo de drenagem é característico de um controle estrutural realizado por sedimentos horizontais ou rochas cristalinas homogêneas e a falta de controle estrutural em rochas de resistência 
uniforme (SUMMERFIELD, 1991).

Tabela 5: Características geométricas da sub-bacia do rio Guamá.

\begin{tabular}{|l|l|}
\hline Característica & Valor \\
\hline Área total $\left(\mathrm{km}^{2}\right)$ & $8.886,16$ \\
\hline Perímetro total $(\mathrm{km})$ & 554 \\
\hline Coeficiente de compacidade, Kc & 1,65 \\
\hline Fator de forma, $\mathrm{F}$ & 0,11 \\
\hline Índice de circularidade, IC & 0,36 \\
\hline Padrão de drenagem & Dendrítico \\
\hline
\end{tabular}

A Figura 2 apresenta a altimetria para a área da sub-bacia do rio Guamá e a Tabela 6 apresenta a porcentagem de ocorrência para cada faixa de altitude na área em estudo. É possível notar que cerca de 78\% do relevo do local atinge até $90 \mathrm{~m}$ de altitude. Em termos de características de relevo a sub-bacia do rio Guamá apresenta altitude mínima $\left(A_{\min }\right)$ de $1 \mathrm{~m}$ e altitude máxima $\left(A_{\text {máx }}\right)$ de $173 \mathrm{~m}$. A amplitude altimétrica $\left(H_{m}\right)$ calculada é de $172 \mathrm{~m}$, o que indica que está sub-bacia não apresenta relevo montanhoso e apresenta relação direta com o índice de rugosidade de uma sub-bacia (ALMEIDA et al., 2016).

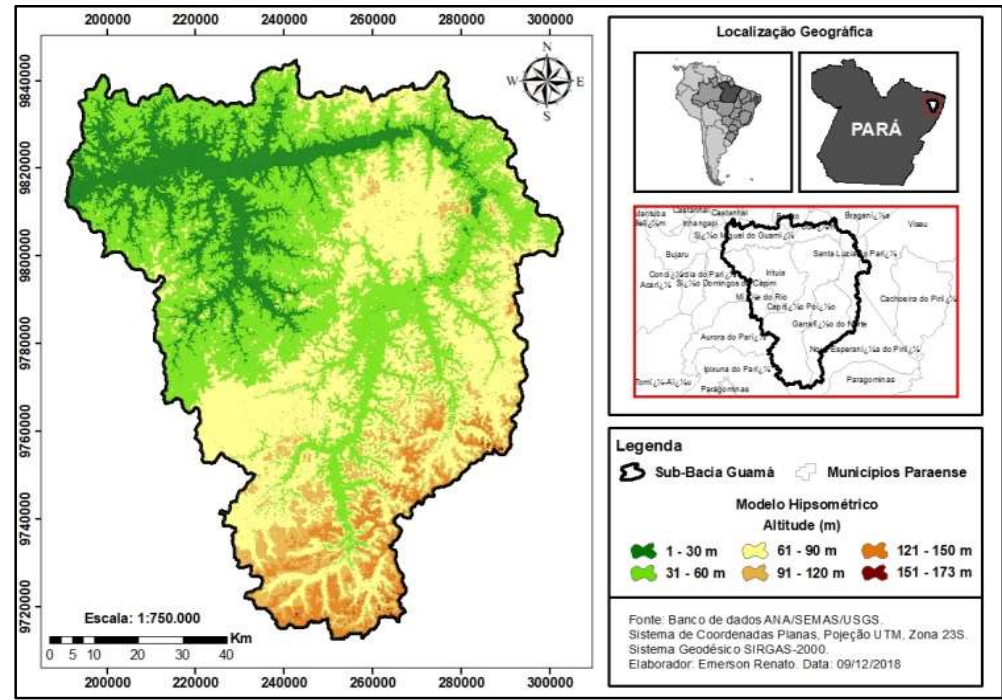

Figura 2: Mapa hipsométrico da sub-bacia do rio Guamá.

Tabela 6: Porcentagem de ocorrência por faixa de altitude.

\begin{tabular}{|l|l|l|l|}
\hline Faixa de altitude & Ponto Médio $(\mathbf{m})$ & No de ocorrência & Porcentagem de ocorrência (\%) \\
\hline $1-30 \mathrm{~m}$ & 15,5 & 3281 & 16,26 \\
\hline $31-60 \mathrm{~m}$ & 45,5 & 6571 & 32,56 \\
\hline $61-90 \mathrm{~m}$ & 75,5 & 5955 & 29,51 \\
\hline $91-120 \mathrm{~m}$ & 105,5 & 2998 & 14,86 \\
\hline $121-150 \mathrm{~m}$ & 135,5 & 1100 & 5,45 \\
\hline $151-173 \mathrm{~m}$ & 162,0 & 274 & 1,36 \\
\hline Total & - & 20.179 & $100 \%$ \\
\hline
\end{tabular}

A variação de altitude e altitude média são fatores importantes, pois a temperatura e precipitação estão relacionadas com a elevação (GERBER et al., 2018; SANTOS et al., 2012). Variações de temperatura influenciam as perdas de águas que ocorrem na forma de evaporação e transpiração, já variações na precipitação atuarão diretamente no escoamento superficial e infiltração (VILLELA et al., 1975). 0 gradiente de canais (Gc) tem por finalidade indicar a declividade dos cursos d'água da bacia (HORTON, 1945; FREITAS, 1952). O valor obtido para a sub-bacia do rio Guamá é igual a $0,61 \mathrm{~m} / \mathrm{Km}$ ou $0,06 \%$, que sugere baixa 
declividade no local e que não há o favorecimento de um escoamento rápido. A relação de relevo (Rr), segundo Schumm (1956), releva que quanto maior o valor de $\mathrm{Rr}$ maior será o desnível entre a cabeceira e o exutório, consequentemente maior será a declividade média da bacia. A Rr obtida para este estudo é igual a 0,61 m/Km. O que corrobora a baixa declividade da área da sub-bacia e corrobora o indicado pelo Gc. Logo, a sub-bacia apresenta baixo desnível entre a cabeceira e o exutório. O relevo de uma bacia hidrográfica apresenta importância fundamental sobre os fatores meteorológicos e hidrológicos, pois a velocidade do escoamento superficial é determinada pela declividade do terreno, enquanto que a temperatura, a precipitação e a evaporação são funções da altitude da bacia.

A Figura 3 apresenta as declividades para a área da sub-bacia do rio Guamá. Por meio deste mapa é possível constatar que a área em estudo apresenta relevo com estrato, principalmente, de baixa declividade.

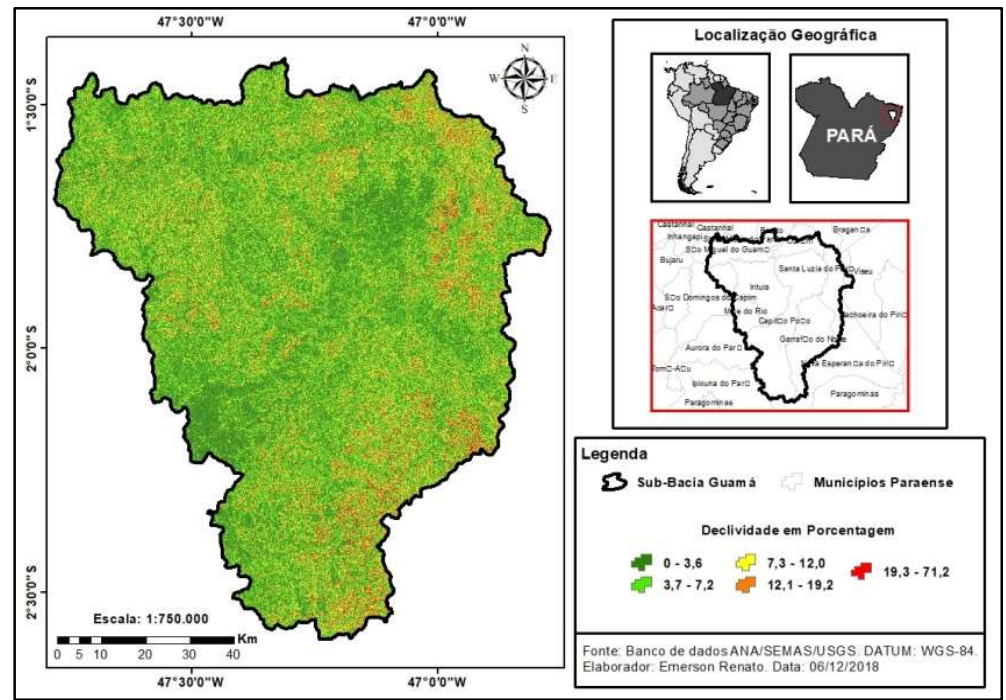

Figura 3: Mapa clinográfica (em porcentagem) da sub-bacia do rio Guamá.

Na área da SBRG identificam-se estratos de relevo plano (declividade de 0 a $3 \%$ ) e suavemente ondulado (declividade de 3 a 8\%), identificados pela predominância da coloração verde forte e clara por toda área da sub-bacia. Somente na porção sul (à esquerda do rio Guamá) e porções nordeste/leste da bacia são encontrados estratos de relevo com forte ondulação (declividade de 20 a 45\%) e montanhosos (declividade de $45 \%$ a $75 \%$ ), onde é atingido um máximo de 71,2\% de declividade (MENDES, 2018). Com isso espera-se uma menor velocidade de escoamento e tempo de concentração maior, que representa o tempo necessário para que toda a bacia esteja contribuindo na seção de saída (SILVEIRA, 2005). Desta forma, não se espera picos de enchentes na área da sub-bacia em estudo, conforme já indicaram os parâmetros geométricos citados anteriormente. De acordo com Mioto et al. (2017) e Barrreto et al. (2017), atividades relacionadas à agricultura e a pecuária que empregam práticas simples de manejo do solo são favorecidas em áreas com inclinação reduzida, pois possuem baixa propensão à erosão do solo e favorecimento da infiltração da água no solo.

A Figura 4 apresenta a hierarquização fluvial da rede de drenagem da sub-bacia hidrográfica do rio Guamá. Com base na hierarquização fluvial é possível destacar que um total de 51,55\% dos canais fluviais é de primeira ordem com um total de $3.667,80 \mathrm{~km}$ de extensão; $24,67 \%$ são de segunda ordem com um total 
de 1.910,6 km de extensão; 13,98\% são de terceira ordem com um total de 967,80 km de extensão; $6,81 \%$ são de quarta ordem com um total de 432,62 km de extensão; 2,05\% são de quinta ordem com 126,82 km de extensão; $3,61 \%$ são de sexta ordem com um total de $216,46 \mathrm{~km}$ de extensão; e, 0,59\% são de sétima ordem com um total de 45,60 km de extensão. Quanto maior a participação percentual de canais de primeira ordem maior é a fragilidade da paisagem, pois os mesmos indicam maior dissecação do relevo, que pode ser provocada por controle estrutural, como falhas, fraturas ou dobramentos (VILELA FILHO et al., 2005). Sabese também que quanto maior o comprimento do rio principal, maior será o número de canais de 1a ordem que o alimenta (SANTOS et al., 2017).

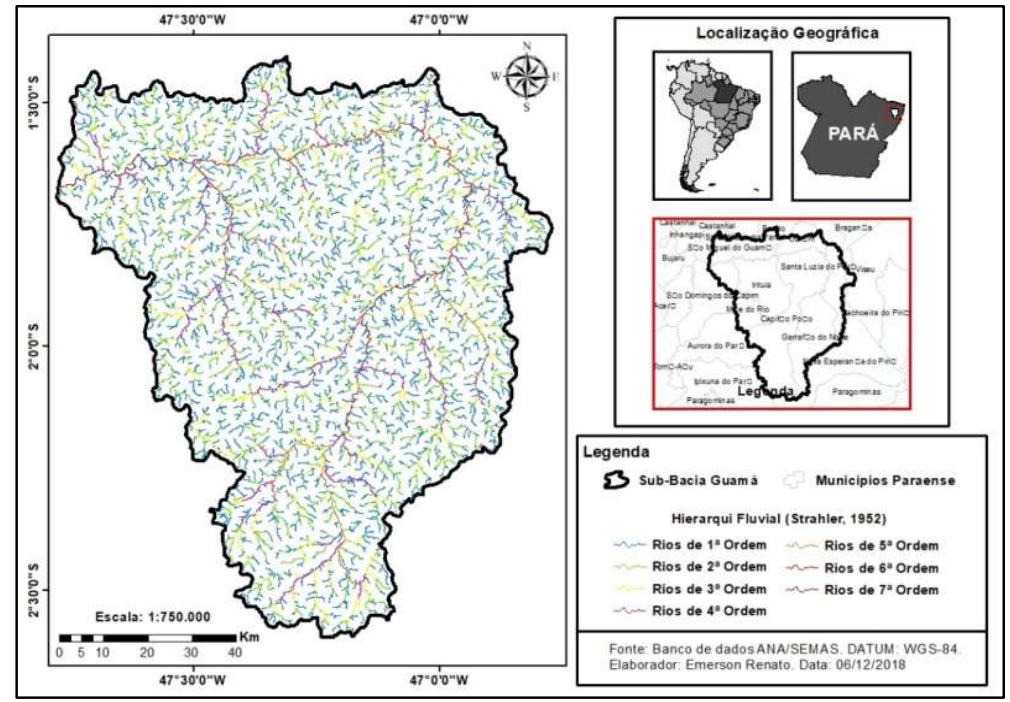

Figura 4: Hierarquização fluvial da rede de drenagem da sub-bacia do rio Guamá.

A Tabela 7 apresenta os valores associados à drenagem da sub-bacia do rio Guamá, onde a SBRG é classificada como de 7ạ ordem, conforme classificação de Strahler (1952).

Tabela 7: Características de drenagem da sub-bacia do rio Guamá.

\begin{tabular}{|l|l|}
\hline Característica & Valor \\
\hline Comprimento total dos cursos d'água (Km) & $7.367,96$ \\
\hline Comprimento do curso d'água principal (Km) & 281,50 \\
\hline Ordenação do curso d'água principal & $7 \underline{a}$ \\
\hline Densidade de drenagem, Dd (Km/Km²) & 0,83 \\
\hline Densidade de rios, Dh (canais/Km²) & 0,66 \\
\hline Extensão do percurso superficial, Eps (m) & 0,60 \\
\hline Índice de rugosidade, Ir (m) & 142,76 \\
\hline
\end{tabular}

De acordo com Beltrame (1994), valores de Dd entre 0,50 e 2,00 Km/ $/ \mathrm{Km}^{2}$ são classificados como medianos. Segundo Christofoletti (1980), valores elevados de Dd indicam áreas com pouca infiltração e melhor estruturação dos canais. Logo, o valor de $\mathrm{Dd}$ de $0,83 \mathrm{Km} / \mathrm{Km}^{2}$ para este estudo sugere que há um escoamento superficial mediano (drenagem mediana pelos canais disponíveis para escoamento), associado a um grau médio de dissecação topográfica em paisagens elaboradas pela atuação fluvial. Segundo Lollo (1995), valores de densidade hidrográfica (Dh) menores que $3 \mathrm{~N} / \mathrm{Km}^{2}$ são classificados como baixos, o que caracteriza a SBRG com baixa capacidade de gerar novos cursos d'água. Segundo os autores Silva et al. (2002), o sistema de drenagem de uma bacia pode ser facilmente alterado, bastando uma pequena mudança de gradiente de descarga do rio motivada, por exemplo, por pequenos ajustes neotectônicos e/ou elevação 
súbita da descarga da bacia, em razão de enxurradas associadas ao desmatamento em grande escala, à montante da bacia, os quais podem levar à erosão basal das margens côncavas, até a formação de barras de sedimentos, nas margens convexas, a jusante.

O valor Eps obtido para a área de estudo representa que 0,60 metros e representa a distância média percorrida pelas enxurradas antes de encontrar um canal permanente, ou seja, o comprimento do caminho percorrido pelas águas pluviais antes de se estabilizarem ao longo de um canal. Para Pinto Junior et al. (2005), a maior parte das observações comprovam a influência no escoamento superficial está relacionada à cobertura vegetal. Isso então coloca peso muito grande na cobertura vegetal, como fator controlador do escoamento superficial.

O índice de rugosidade evidencia maior diversidade de ambientes e maior movimento do relevo, o que implica na variação das declividades e comprimento das vertentes, além da dimensão das drenagens. A declividade influencia na infiltração e nos processos erosivos, em função do escoamento superficial indica a dissecação do relevo. Quanto maior esse coeficiente, mais restritiva serão as possibilidades de uso (irrigação, por exemplo) (MACHADO et al., 2011). Entretanto, para a sub-bacia em estudo, o valor de 142,76 metros pode ser considerado baixo, principalmente devido às baixas porcentagens de declividade da área e grau médio de dissecação do relevo. O valor encontrado neste estudo é favorável a utilização da sub-bacia em atividades agropecuárias.

\section{Análise de Uso e Ocupação do Solo}

A Tabela 8 apresenta os valores de área (em hectare e $\mathrm{km}^{2}$ ) e de porcentagem (\%) quanto ao uso e ocupação do solo na sub-bacia do rio Guamá com variações diversificadas.

Tabela 8: Uso e ocupação do solo na sub-bacia do rio Guamá.

\begin{tabular}{|l|l|l|l|}
\hline Classes & Área (hectare) & Área $\left.\mathbf{( k m}^{\mathbf{2}}\right)$ & Porcentagem (\%) \\
\hline Vegetação densa & $162.084,66$ & $1.620,84$ & 18,36 \\
\hline Vegetação secundária & $210.249,87$ & $2.101,49$ & 23,82 \\
\hline Vegetação rasteira & $177.701,29$ & $1.777,01$ & 20,13 \\
\hline Solo exposto & $328.940,99$ & $3.289,40$ & 37,26 \\
\hline Água & $3.857,29$ & 38,57 & 0,44 \\
\hline
\end{tabular}

*Porcentagem em relação à área total ocupada pela classe na sub-bacia.

A SBRG, como tantas outras bacias e sub-bacias hidrográficas no Brasil, é afetada por impactos ambientais oriundos do processo de ocupação desordenado e acelerado do solo. Atualmente, a sub-bacia está ocupada por $18,36 \%$ de área de vegetação densa e 23,82\% de vegetação secundária. Totalizando 42,18\% a ocorrência de áreas com a presença de algum tipo de vegetação (Tabela 6). A classe de vegetação rasteira encontrada pode estar associada com área de pastagem ou gramíneas, por isso não foram consideradas como área com vegetação. A área classificada como solo exposto representa a maior porcentagem (37,26\%) para uma classe individual dentro da sub-bacia. Esta última classificação representa áreas sem nenhum tipo de vegetação e que representa falta de proteção ao solo com consequências negativas como a perda de água.

A vegetação densa, também chamada de vegetação primária, possui elevada expressão local, com grande diversidade biológica e interferências antrópicas mínimas sem que haja alteração de suas 
características estruturais primárias e de espécies (BRASIL, 2009). Moraes et al. (2016) destacam a associação entre a preservação da vegetação ciliar (vegetação característica de margens ou áreas adjacentes a corpos d'água, e pode ser considerada um ecossistema ripário) (LIMA, 1976) e à manutenção das diversas funções e serviços ecológicos, pois funciona como um sistema tampão que filtra os poluentes e como fonte de troca de matéria, energia e organismos. Desta forma, destaca-se a necessidade de restauração da vegetação primária, principalmente a vegetação ciliar no entorno de rios e nascentes no interior da sub-bacia. Afinal, este tipo de vegetação ainda atua como fonte de matéria e energia, refúgio de vida silvestre, filtro de nutrientes, controlador de temperatura e produtividade da água, além de servir de conexão entre paisagens e proteção contra a erosão, entre outros (ROMERO et al., 2014).

Ainda segundo Brasil (2009), a vegetação secundária, ou de regeneração, é o resultado de um processo natural avançado de regeneração da vegetação arbustiva e/ou arbórea (sucessão) devido ações humanas ou naturais que levaram a supressão total ou parcial da vegetação primária com possibilidade de ocorrência de espécies remanescentes originais. A classe de vegetação secundária também se destaca com, aproximadamente, $24 \%$ do total e pode ser encontrada em diferentes estágios de desenvolvimento. De forma geral, representa um prognóstico favorável da existência de áreas com vegetação em processo de recuperação ou restauração, seja natural ou artificial. Segundo Belato et al. (2019), a origem da vegetação secundária está relacionada ao abandono da terra após a utilização pelo homem para finalidades como a mineração, agricultura ou pecuária

A vegetação rasteira é constituída pela presença de gramíneas e que podem estar associadas às áreas de pastagem (PORTO et al., 2017). A quantidade encontrada para esta classe, aproximadamente $20 \%$, supera a classe de vegetação densa, com aproximadamente $18 \%$. A classe de solo exposto (cerca de $37 \%$ ) está associada a presença do homem e as alterações realizadas na superfície do solo. As transformações antrópicas da área da sub-bacia do rio Guamá podem estar relacionadas ao crescimento demográfico que os municípios da região vêm sofrendo ao longo dos anos, surgimento de indústrias e outros empreendimentos dependentes de uso de água, crescimento das atividades de agricultura e pecuária licenciadas e não licenciadas, mineração, entre outros. Segundo Neves et al. (2019), as principais contribuições para o processo de expansão dos centros urbanos são provenientes das áreas de vegetação rasteira seguida da classe solo exposto. Notou-se durante as visitas de campo na região da SBRG a existência de muitas áreas destinadas à pastagem localizadas nas margens do rio Guamá e seus afluentes. Este uso acarreta problemas como o assoreamento dos rios, pisoteio de suas margens, aumento das taxas de exportação de nutrientes para os corpos d'água, entre outros (MORAES et al., 2016). Silva et al. (2019) estudando a Reserva do Alto Rio Guamá, situada no município de Paragominas (nordeste paraense) entre os rios Guamá e Gurupi, constataram reduções na cobertura vegetal devido à expansão de atividades de agricultura e exploração madeireira.

Através da observação da Figura 5 nota-se a distribuição espacial das classes de uso e ocupação da terra na área de estudo. Verifica-se que, principalmente, a porção central/sudoeste da SBRG (entre a Br-010 e o rio Guamá) é composta por diversas áreas classificadas como solo exposto. A vegetação densa (ou primária) está representada por áreas dispersas na sub-bacia com as maiores manchas ocorrendo a norte, 
leste (referente a um trecho da Terra Indígena do Alto Rio Guamá nas proximidades da comunidade Boca Nova) e sudoeste (em Ipixuna do Pará) da sub-bacia. As áreas classificadas como vegetação secundária e vegetação rasteira encontram-se dispostas nas bordas das manchas que representam áreas de vegetação densa.

A baixa declividade do terreno é favorável ao cultivo de espécies agrícolas (CORSEUIL et al., 2007), representadas nessa região pelo cultivo do dendê, cítricos, pimenta-do-reino, entre outras. A marcante presença de solo exposto foi observada em toda a área da SBRG. Atualmente, quando se percorre a SBRG é possível observar diferentes tipos de ocupação que suprimem a vegetação e mudam as feições dos rios para construção de habitações, desenvolvimento dos centros urbanos, pequenas comunidades, atividades agropecuárias e extrativistas (carvoaria, seixeira e madeireira), acarretando transtornos à sociedade. Segundo Silva et al. (2016), na mesorregião do nordeste paraense destacam-se os fatores mineração, ocupação humana (população) e agricultura no uso e cobertura do solo. No entanto, pouco se conhece sobre os efeitos das mudanças no uso da terra no funcionamento, estrutura e qualidade desse rio. Em função de sua localização, área de abrangência, propriedades físico-bióticas, características socioeconômicas e uso da água para abastecimento público, a sub-bacia do rio Guamá possui diversos conflitos ambientais que são acentuados pelo crescimento das atividades agropecuárias.

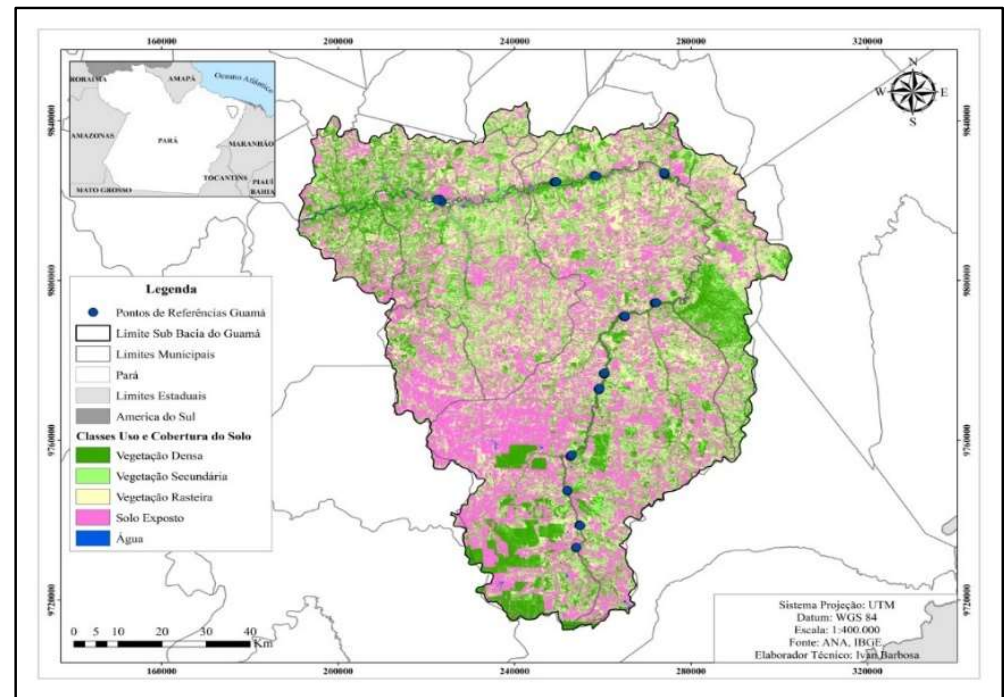

Figura 5: Mapa de uso e ocupação da terra na sub-bacia do rio Guamá.

O IBGE (2016) no Relatório de Mudanças na Cobertura e Uso da Terra relata que na porção nordeste do Pará, próximo à divisa com Maranhão, antigas pastagens têm dado lugar ao cultivo de soja e as extensas plantações de dendezeiros, do qual é extraído o óleo utilizado na produção de biodiesel, alimentos e cosméticos.

De acordo com Silva et al. (2018), as características favoráveis do solo de uma determinada região, como: fertilidade, umidade, estabilidade, etc.; podem favorecer o estabelecimento de atividades agropecuárias nas margens ciliares. Ainda segundo os autores, o manejo inadequado nesse sistema de uso do solo pode provocar a compactação dos solos devido ao pisoteio do gado e a utilização de máquinas agrícolas; eutrofização ou contaminação dos cursos d'água devido ao uso de corretivos agrícolas e/ou 
agrotóxicos para desenvolvimento de culturas; produção de sedimentos (erosão) e deposição nos cursos d'água (assoreamentos) caso não seja realizado o adequado sistema de plantio (plantio direto ou convencional), adotando quando necessário práticas conservacionistas como, por exemplo, o terraceamento.

As áreas que apresentam maior quantidade de vegetação densa estão localizadas, principalmente, às margens do rio Guamá. Estas são caracterizadas como Áreas de Preservação Permanente (APP's), conforme o Código Florestal brasileiro (BRASIL, 2012), no que diz respeito à manutenção da floresta natural ao longo dos rios e nascentes. No que tange está legislação, são estabelecidas faixas de preservação da vegetação (variando de 30 a $500 \mathrm{~m}$ ) de acordo com a largura do leito de cursos d'água (inferiores a $10 \mathrm{~m}$ até casos superiores a $600 \mathrm{~m}$ ).

As Figuras $6 a, 6 b$ e $6 c$ apresentam três recortes da sub-bacia de acordo com os pontos amostrais coletados durante as visitas de campo. A Figura 6a apresenta a visualização aproximada do uso e ocupação da terra na área da SBRG, em relação aos pontos 1 a 4, denominada de alto rio Guamá. A Figura 6b apresenta a visualização aproximada da área da SBRG, em relação aos pontos 5 a 8, denominada de médio rio Guamá. A Figura $6 c$ apresenta a visualização aproximada do uso e ocupação da terra na área da SBRG, em relação aos pontos 9 a 12, denominada de baixo rio Guamá. Vale destacar que para cada ponto (1 a 12) foram georreferenciadas três localizações diferentes (A, B e C) para maior precisão.
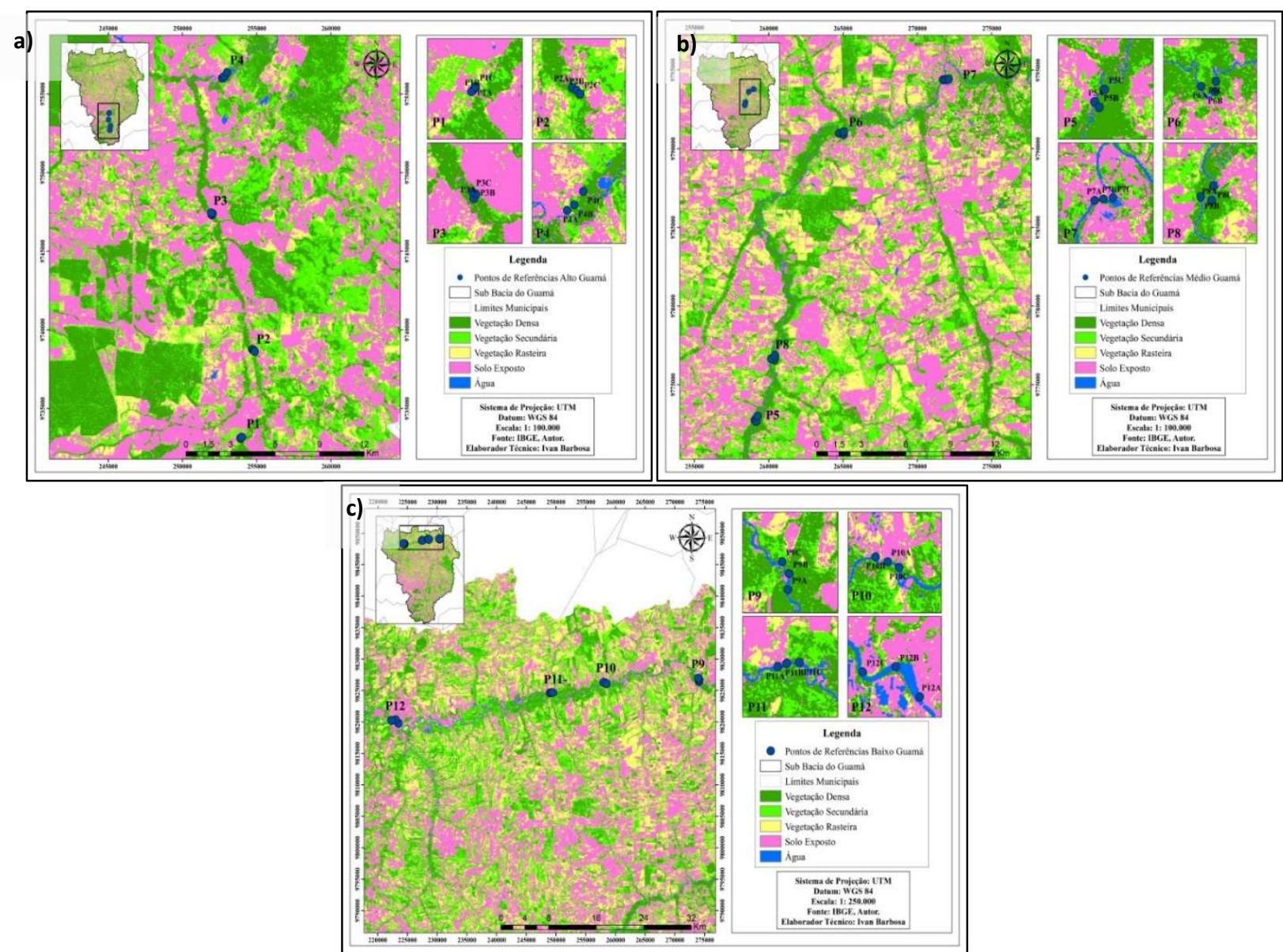

Figura 6: Mapas de uso e cobertura do solo da área de estudo nas regiões do: (a) alto rio Guamá; (b) médio rio Guamá; (c) baixo rio Guamá. 
A área apresentada na Figura 6a pode ser considerada como a região da SBRG mais próxima da nascente do rio e se localiza em uma área de maior altitude: acima de 61 metros nas áreas distantes dos pontos coletados aonde a altitude chega entre 31 a 60 metros, com diversos picos de 121 a 150 metros na parte sul e leste; declividade entre 0 e $7,2 \%$ com diversos picos acima de $19,3 \%$ à direita dos pontos amostrais. Nesta área identifica-se que as elevadas altitudes estão associadas às áreas de maior quantidade e volume de vegetação densa (ao sul e leste da SBRG). Assim como, a forte presença de solo exposto na forma de grandes manchas distribuídas por toda a área recortada, principalmente nas regiões de menor altitude e menor declividade. Também são identificadas pequenas manchas classificadas como vegetação secundária e rasteira na porção norte da área (menor altitude e declividade), manchas medianas de vegetação secundária na porção leste (maior altitude e declividade) e manchas medianas de vegetação rasteira na porção sul (maior altitude e declividade).

O recorte de área apresentado para a porção média do rio Guamá (Figura 6b) também apresenta grande quantidade de áreas classificadas como solo exposto na forma de diversas pequenas manchas distribuídas por toda região em destaque. Enquanto que, a quantidade de vegetação densa identificada é menor, concentrando-se, principalmente, em maior volume às margens do rio Guamá e seus tributários e em pequenas manchas distribuídas pela área recortada. Nesta porção da SBRG é possível identificar uma maior quantidade de manchas de vegetação rasteira e poucas de vegetação secundária. Vale destacar que a área recortada apresenta declividade variando 0 a 7,2\% com poucas ocorrências de áreas com declividade entre 7,3 a 19,2\%, ou seja, um relevo mais plano do que a área do alto rio Guamá. Associado a declividade, verificam altitudes menores (61 a 90 metros), com poucas ocorrências de altitudes acima de 91 metros na porção sudeste da área recortada.

A Figura 6c, que apresenta a área correspondente ao baixo rio Guamá, possui as menores altitudes, predominantemente variando de 0 a 30 metros. Podendo atingir em determinadas áreas altitudes de 31 a 60 metros. Para a área também é possível atribuir as menores porcentagens de declividade $(0$ a 3,6\%) ao relevo. Quanto ao uso e ocupação da terra é possível identificar áreas distribuídas em pequenas manchas de solo exposto por toda região, principalmente na porção sul. As manchas relacionadas à vegetação secundária e rasteira também se apresentam com distribuição por toda área recortada, principalmente nas proximidades do rio Guamá. Vale destacar a ausência de vegetação nas margens do rio Guamá localizada no ponto 12 , pois se trata da área urbana do município de São Miguel do Guamá, ou seja, áreas de APP sendo parcialmente ocupadas ou desmatadas. Neste trecho encontram-se localizadas as áreas urbanas de dois importantes municípios para a região: São Miguel do Guamá e Ourém.

Desta forma, identificou-se que na área de estudo existem em torno do rio Guamá, e seus afluentes, muitas áreas destinadas a atividades humanas (representando principalmente pela porcentagem de área de solo exposto). Uma associação negativa que provoca sérias consequências para o rio principal e seus afluentes, margens, entre outros problemas. O monitoramento da cobertura vegetal é muito importante, pois a presença de tal contribui para o ajustamento das variáveis internas dos ecossistemas aquáticos e a manutenção do equilíbrio do regime hidrológico de uma região hidrográfica (MORAES et al., 2016). Celentano 
et al. (2018) em estudos acerca do desmatamento, degradação e violência abrangendo o no leste do Pará (nordeste paraense) ressaltaram a importância da conservação e restauração das florestas, assim como a implementação de políticas públicas complementares para regulação das atividades de silvicultura, agrícola e pecuária no bioma Amazônia.

No geral, os resultados indicaram que a metodologia utilizada na classificação é considerada satisfatória, pois o índice Kappa geral obtido neste estudo foi igual a 0,8950. Assim, foi obtido um índice de relevância quase perfeita (LANDIS et al., 1977). Os índices Kappa individuais para vegetação densa $(0,8522)$, vegetação secundária $(0,8267)$, vegetação rasteira $(0,8276)$, solo exposto $(0,8741)$ e água $(1)$ também foram todos classificados semelhantemente ao índice geral.

\section{Análise Regional da Precipitação Pluvial}

A distribuição espacial da chuva média anual entre os anos de 2015 e 2017 (Figura 7a) demonstrou que os menores valores (mínimo de $2.295 \mathrm{~mm}$ ) são encontrados na porção esquerda da SBRG, enquanto que os maiores valores (máximo de $2.729 \mathrm{~mm}$ ) na porção direita (mais próxima do litoral). Logo, identifica-se uma diferença de $434 \mathrm{~mm}$ de amplitude na quantidade de chuvas na área de estudo. Estudos relacionados às precipitações anuais na Amazônia Oriental evidenciaram que estas tendem a decrescer do setor costeiro para o interior, decorrente da maneira como se originam os sistemas de circulação ao penetrarem a região (NIMER, 1989; FIGUEROA et al., 1990; FISCH et al., 1998; GRIMM, 2011).

A Figura $7 b$ apresenta a distribuição espacial da precipitação pluvial para o período chuvoso (dezembro a maio), enquanto que a Figura 7c apresenta esta distribuição para o período menos chuvoso (junho a novembro). Em ambos os períodos sazonais é possível observar o mesmo comportamento crescente da quantidade de chuva do interior da sub-bacia (à esquerda) para a parte mais próxima à costa litorânea (à direita).

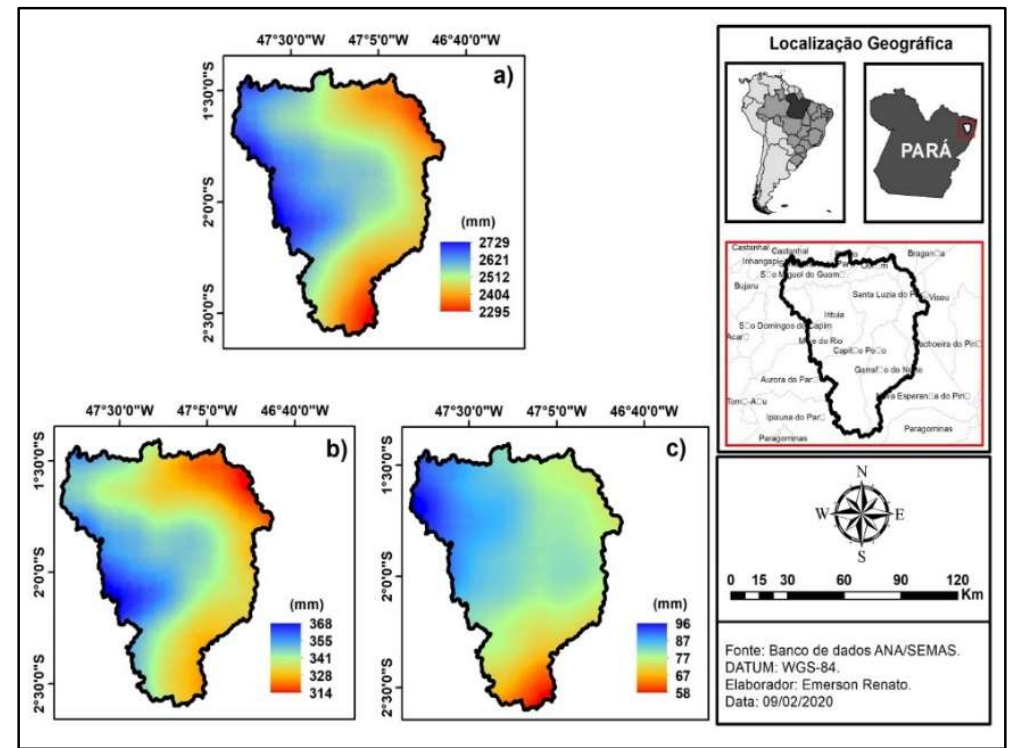

Figura 7: Distribuição espacial dos dados de CHIRPS da: (a) precipitação pluvial média anual; (b) precipitação acumulada média para o período chuvoso (dezembro a maio); e, (c) precipitação acumulada média para o período menos chuvoso (junho a novembro) para o período de 2015 a 2017.

Ainda é possível destacar que no período mais chuvoso (Figura 7b) a porção à nordeste da SBRG 
apresenta os menores valores de chuva (mínimo de $314 \mathrm{~mm}$ ) e a porção sudoeste/noroeste os maiores valores (máximo de $368 \mathrm{~mm}$ ). No período menos chuvoso (Figura 7c), as áreas com os menores valores de chuva encontram-se ao sul da SBRG (mínimo de $58 \mathrm{~mm}$ ). Como esperado, a porção oeste/noroeste apresenta as maiores quantidades de chuva (máximo de $96 \mathrm{~mm}$ ), devido sua proximidade com a costa litorânea paraense.

Destaca-se que as chuvas tendem a se concentrar na porção sudoeste/oeste/noroeste da sub-bacia, as quais são áreas com as menores altitudes, com exceção da porção sudoeste, e com as menores porcentagens de declividade (relevo plano). Nas porções sudoeste e noroeste foram encontradas grandes manchas de vegetação densa que são favoráveis à manutenção das chuvas e do volume de água no rio Guamá. Entretanto, na porção oeste foram identificadas apenas pequenas manchas de vegetação densa e uma predominância de áreas de classe solo exposto e vegetação rasteira. Estes dois usos não são favoráveis à manutenção do volume de chuvas e dos corpos d'água da região.

\section{Análise da Vulnerabilidade Ambiental}

As superfícies e porcentagens das áreas de vulnerabilidade ambiental para a área de estudo são apresentadas na Tabela 9, onde se observa que a classe de maior ocorrência corresponde à vulnerabilidade média (29\%). Enquanto que, $41,80 \%$ da área da SBRG apresenta vulnerabilidade baixa ou muito baixa em oposição aos $29,19 \%$ de área da SBRG classificada como vulnerabilidade alta ou muito alta.

Tabela 9: Vulnerabilidade ambiental, em $\mathrm{km}^{2}$, na área da sub-bacia do rio Guamá.

\begin{tabular}{|l|l|l|}
\hline Classes & Área $\mathbf{( k m}^{2} \mathbf{)}$ & Porcentagem (\%)* \\
\hline Muito baixa & $1.245,37$ & 14,06 \\
\hline Baixa & $2.457,17$ & 27,74 \\
\hline Média & $2.568,60$ & 29,00 \\
\hline Alta & $2.312,66$ & 26,11 \\
\hline Muito alta & 272,81 & 3,08 \\
\hline
\end{tabular}

*Porcentagem em relação à área total ocupada pela classe na sub-bacia.

A representação cartográfica da vulnerabilidade ambiental resultante da combinação das variáveis físico-geográficas selecionadas é mostrada na Figura 8, onde é possível observar a distribuição espacial das classes (em quilômetros quadrados e porcentagem de área). De forma geral, é possível observar o comportamento das variáveis físicas naturais (geologia, tipo de solo, declividade, tipo de vegetação, e precipitação pluvial) diante da interferência do homem sobre a terra. Esta pressão se torna evidente, principalmente, na porção sul da SBRG onde nota-se um grande aglomerado de áreas, representadas pelas manchas vermelhas medianas, que indicam vulnerabilidade ambiental muito alta. Estas interferências antrópicas são ainda mais importantes, devido às proximidades com as maiores áreas classificadas como sendo de vulnerabilidade muito baixa. O que levanta profunda preocupação com a integridade da cobertura vegetal primária e dos ecossistemas aquáticos, pois a montante desta área encontra-se a nascente do rio Guamá. Outras pequenas áreas de vulnerabilidade muito alta são observadas em determinadas partes da área da SBRG, principalmente ao norte, pois estão associadas aos centros urbanos dos municípios de Ourém, Capitão Poço, São Miguel do Guamá e comunidades em processo de expansão e crescimento demográfico, 
como as comunidades de Muriá, Poção, Boca Nova, Igarapé-Açú etc.. Percebe-se também uma grande concentração de áreas correspondentes à vulnerabilidade muito baixa e baixa na porção central, norte e, principalmente, a noroeste da SBRG. As categorias de vulnerabilidade alta e média estão distribuídas aleatoriamente por toda área de estudo.

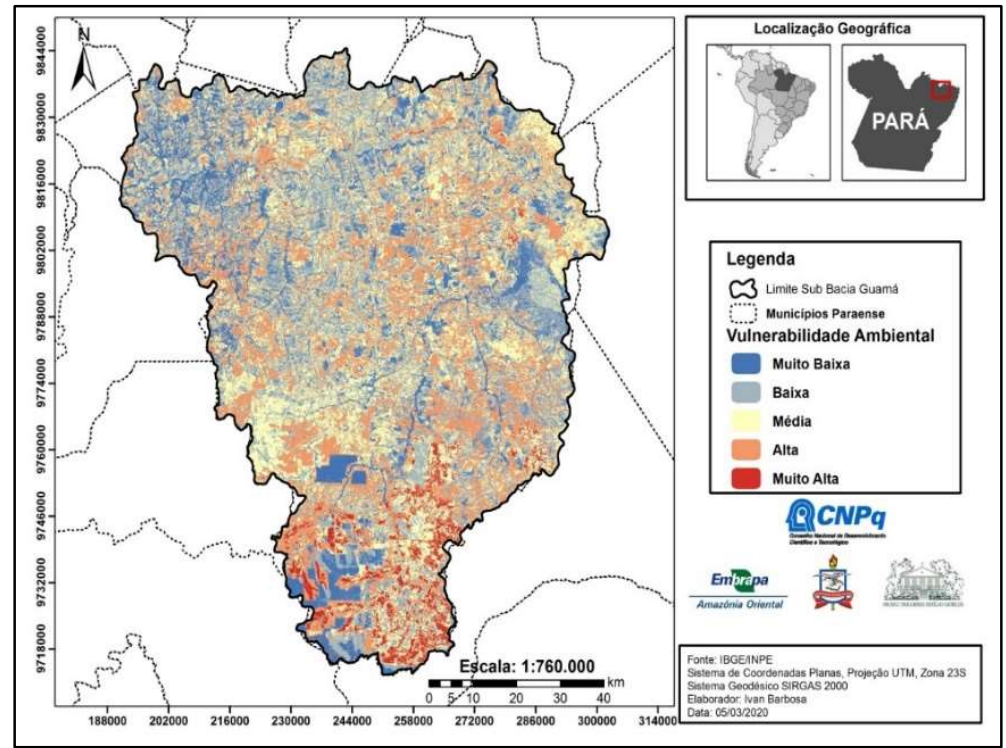

Figura 8: Mapa de vulnerabilidade natural da sub-bacia do rio Guamá.

Quanto ao tipo de cobertura vegetal, na área da SBRG foi atribuído o grau de vulnerabilidade 1 ao tipo composto por floresta densa aluvial. Este tipo de vegetação encontra-se presente, principalmente, ao longo das margens do rio Guamá (em destaque o trecho entre a comunidade de Muriá e o centro urbano de São Miguel do Guamá) e na porção sudoeste da sub-bacia. Também foi encontrado na área o tipo de vegetação classificada como secundária, a qual foi atribuída o grau de vulnerabilidade igual a 1,5. A vegetação secundária é encontrada em grande parte na porção central (municípios de Garrafão do Norte e Mãe do Rio) e sudeste (Garrafão do Norte), com destaque à forte presença deste tipo de vegetação em quase todo território do município de Irituia. A floresta densa aluvial e a vegetação secundária atuam diminuindo os impactos de fatores externos aos locais em que recobrem e os tornam morfodinamicamente estáveis (BELATO et al., 2018)

Quanto aos tipos de solo predominantes na região, destaca-se a forte presença do tipo latossolo em toda a área da SBRG, principalmente na porção central e parte superior. Este tipo de solo recebeu o grau de vulnerabilidade igual a 1. Também foi encontrado solo do tipo argissolo, grau de vulnerabilidade igual a 2, na região das comunidades de Boca Nova e Furo Novo no município de Capitão Poço. Em ordem decrescente, os solos do tipo plintossolo, gleissolo e neossolo foram encontrados em menores quantidades na área da sub-bacia. Para estes três últimos tipos de solo foi atribuído o grau de vulnerabilidade igual a 3. O solo do tipo plintossolo ocorrendo de forma concentrada na porção sul; o solo do tipo gleissolo ocorrendo nas margens do rio Guamá no trecho entre a comunidade de Muriá e o centro urbano de São Miguel do Guamá; e, o solo do tipo neossolo ocorrendo minimamente em uma pequena área no município de Irituia. Leite et al. (2013) e Feitosa et al. (2010) destacam que o elemento pedologia relaciona a maturidade dos solos à um 
menor grau de vulnerabilidade. Ainda segundo os autores, os latossolos são solos mais profundos, porosos, textura elevada, moderada taxa de infiltração, bem formados (mais estáveis) e apresentam maior resistência e tolerância à erosão.

Quanto à geologia da área de estudo foi encontrado o tipo Granito, grau de vulnerabilidade igual a 1,1, abrangendo grande parte da SBRG presente nos municípios de São Miguel do Guamá, Bonito, Ourém, Capitão Poço, Irituia, Mãe do Rio e em uma pequena área na porção leste do município de Santa Luzia do Pará. O grau de vulnerabilidade igual a 1,7 foi atribuído a Formação Vila Cristal (em uma pequena área a leste da sub-bacia) e Grupo Gurupi (no extremo norte do município de Garrafão do Norte e em grande parte do município de Santa Luzia do Pará). Também foi encontrado o tipo Arenito Guamá, grau de vulnerabilidade igual a 2,4, localizado em uma área na porção leste de São Miguel do Guamá e norte de Irituia. Por fim, em proporção decrescente de ocorrência, os tipos geológicos Formação Ipixuna, Cobertura Detrito-Laterítica Paleogênica, Aluviões Holocênicos e Cobertura Detrito-Laterítica Pleistocênica foram classificados com grau de vulnerabilidade igual a 3. De acordo com Belato et al. (2018), apresenta menor vulnerabilidade as formações geológicas mais antigas, devido sua maior resistência a erosão (maior grau de coesão das rochas). O tipo Formação Ipixuna do Período Terciário foi encontrado em grande parte do município de Garrafão do Norte, e na porção sul dos municípios de Santa Luzia do Pará e Mãe do Rio. O tipo Cobertura Detrito-Laterítica Paleogênica foi observado na parte sul da SBRG distribuído entre o tipo Formação Ipixuna nos municípios de Garrafão do Norte e Capitão Poço. A geologia do tipo Aluviões Hologênicos foi observada ocorrendo às margens do rio Guamá (no trecho entre a comunidade de Muriá e o centro urbano de São Miguel do Guamá) semelhantemente ao solo do tipo gleissolo. A geologia do tipo Cobertura Detrito-Laterítica Pleistocênica foi encontrada somente em uma área localizada entre o limite dos municípios de Irituia e Mãe do Rio.

As variáveis físico-geográficas declividade, uso e ocupação da terra e precipitação pluvial já foram anteriormente discutidas em termos de suas distribuições espaciais. Porém, ressaltam-se os graus de vulnerabilidade atribuídos para as classes encontradas para a área da SBRG. Para a declividade foram atribuídos graus de vulnerabilidade conforme aumento da porcentagem de inclinação: $0-2,2-6,6-20,20$ - 50 e maior que 50 , respectivamente, $1,1,5,2,2,5$ e 3. A precipitação pluvial para a área em estudo apresentou grau de vulnerabilidade igual a 1,6, ou seja, precipitação mensal em torno de 183 a $200 \mathrm{~mm}$ nas porções nordeste e sudeste. Em maior proporção, o grau de vulnerabilidade igual a 1,8 (225 a $250 \mathrm{~mm} / \mathrm{mês)}$ foi aplicado para toda parte central, norte e sul da SBRG. Entretanto, a declividade e o clima (representado pela precipitação pluvial) não demostraram apresentar influência como fatores modeladores da vulnerabilidade ambiental. Duarte et al. (2017), encontraram resultados semelhantes de que o clima não é o principal fator degradante para o município de Paragominas localizado no nordeste paraense. Quanto as classes de uso e ocupação da terra, foi atribuído grau de vulnerabilidade igual a 1 para corpo hídrico e vegetação densa; grau de vulnerabilidade igual a 1,5 para a classe vegetação secundária; e graus de vulnerabilidade iguais a 2 e 3 para vegetação rasteira e solo exposto, respectivamente.

As áreas classificadas como vulnerabilidade ambiental muito baixa e baixa estão localizadas predominantemente em solos do tipo latossolo; os tipos de geologia comumente encontrados foram 
Granito, Arenito Guamá e Cobertura Detritro-Laterítica Paleogênica; a cobertura vegetal encontrada, semelhantemente a variável uso e ocupação da terra, é composta geralmente por floresta densa aluvial, e em alguns casos, por vegetação secundária; por fim, a declividade e a precipitação pluvial não se mostraram fatores importantes para o estabelecimento da vulnerabilidade ambiental. Para as áreas de vulnerabilidade ambiental média notou-se a importância da presença de vegetação secundária e a ocorrência de solo exposto/vegetação rasteira como fatores comuns para todas as ocorrências identificadas no mapa. Nas áreas classificadas como de vulnerabilidade ambiental alta e muito alta foi observada a similaridade quanto à ocorrência do plintossolo como tipo de solo, a presença da Formação Ipixuna quanto à geologia, a ocorrência das áreas com maiores porcentagens de declividade e a forte presença de áreas antropizadas/solo exposto.

No trabalho de Rocha et al. (2020) foi avaliado o índice de sustentabilidade hídrica para a bacia do rio Guamá considerando sua extensão até a foz na baía do Guajará em Belém. As autoras identificaram que as principais áreas alteradas, segundo o indicador ambiental constituído pelo uso e ocupação do solo, são representadas pelas regiões do Igarapé Mãe do Rio e Alto Rio Guamá, corroborando os resultados encontrados neste trabalho. $O$ indicador hidrológico também corrobora os resultados deste trabalho ao indicar menor escoamento superficial da precipitação incidente, principalmente na área do Alto Rio Guamá.

\section{CONCLUSÕES}

Os valores das características morfométricas que a sub-bacia do rio Guamá apresenta mostram que a área tem formato mais alongado ( $F$ baixo), distanciando-se da área de um círculo (Kc maior que 1) e apresenta baixo potencial para ocorrência de inundações em condições normais de precipitação. Os valores de Dh e Dd indicam que a SBRG possui capacidade mediana de gerar novos cursos d'água, um escoamento superficial razoavelmente baixo e uma pequena dissecação associada. Apesar de ser constituída por 51,55\% de canais de 1aㅡ ordem, o que pode explicar sua baixa densidade de drenagem. A característica plana da subbacia exerce forte influência nestes resultados. Seu relevo é predominantemente plano com suaves ondulações, e sua declividade varia de 0 a 71,2\%. Assim, a área de estudo apresenta características físicas desfavoráveis ao abastecimento hídrico por se localiza em altitude baixa e não ser bem drenada. Contudo, os resultados apresentados pelas características do relevo sugerem o favorecimento de baixo escoamento da água e baixa susceptibilidade à erosão e alagamentos.

Em relação a quantidade de chuva foram registados, entre os anos de 2015 e 2017, elevados valores de precipitação e que apresentam uma distribuição característica. Apesar de regulares, não se distribuem igualmente ao longo do ano e demonstram concordância com o comportamento esperado para a região ao apresentar um período considerado chuvoso (dezembro a maio) e um período menos chuvoso (junho a novembro). A distribuição da quantidade de chuva aumenta com a proximidade da costa oceânica do estado do Pará (de lesta à oeste). Os valores de mínimo e máximo de chuva no período chuvoso ( $314 \mathrm{~mm}$ e $368 \mathrm{~mm}$, respectivamente), período menos chuvoso (58 $\mathrm{mm}$ e $96 \mathrm{~mm}$, respectivamente) e anual (2.295 mm e 2.729 $\mathrm{mm}$, respectivamente) representam altos valores de precipitação e, consequentemente, de escoamento superficial para os rios. 
A sub-bacia do rio Guamá, como tantras outras bacias e sub-bacias hidrográficas no Brasil, enfrenta problemas ambientais provenientes da expansão do uso e ocupação desornada do solo. Além de situa-se em uma área de elevado desenvolvimento econômico e expansão das atividades agropecuárias. Notou-se na área de estudo maior porcentagem (aproximadamente 57\%) de área classificada como solo exposto e vegetação rasteira do que área classificada como vegetação densa ou secundária (aproximadamente 42\%). A redução e a ausência de cobertura vegetal primária em alguns trechos da SBRG foram evidenciadas e demonstra-se a importância do monitoramento deste tipo de cobertura para o equilíbrio das variáveis dos ecossistemas aquáticos (estabilidade dos ciclos biogeoquímicos), qualidade da água e a manutenção do regime de chuva na área da sub-bacia hidrográfica (ciclo hidrológico), dependem da presença de cobertura vegetal e dão condições de sustentabilidade ao múltiplos uso na SBRG. Logo, sugere-se a adoção de medidas de restauração nas áreas de vulnerabilidade ambiental alta e muito alta; de proteção das áreas classificadas como vulnerabilidade média, baixa e muito baixa; e de recuperação e preservação da mata ciliar nas áreas de nascentes no interior da sub-bacia.

As áreas de vulnerabilidade alta e muito alta foram impactadas negativamente pelos indicadores geológico (rochas sedimentares da Formação Ipixuna), tipo de solo (plintossolo) e uso e ocupação (solo exposto); onde foram identificados solos frágeis, rochas recentes e forte presença de atividades antrópicas (representadas pelas atividades agropecuárias e urbanização dos centros urbanos dos municípios) que resultam na retirada da cobertura vegetal natural. Nas áreas de vulnerabilidade baixa e muito baixa as variáveis tipo de solo (latossolo), geologia (Granito), tipo de cobertura vegetal (floresta densa aluvial) e uso e cobertura (vegetação densa e secundária) apresentaram-se menos vulneráveis à degradação ambiental. Ressalta-se que as áreas de vulnerabilidade média sofrem influência, principalmente, devido a presença da vegetação secundária e de atividades antrópicas de média degradação ambiental. Na SBRG as áreas de baixa, média e alta vulnerabilidade apresentaram as maiores porcentagens de ocorrência (aproximadamente 28\%, 29 e 26\%, respectivamente); e, representam áreas com a constante ação de processos pedogênicos e morfogênicos. Desta forma, ressalta-se a importância do controle da expansão das atividades antrópicas, retirada da vegetação primária e o respeito aos preceitos legais da legislação ambiental brasileira.

Contudo, é fundamental que mais estudos científicos sejam realizados para compreender as limitações e problemas ambientais da região, como: avanço das pastagens e cultivos agrícolas, falta de manejo adequado do solo, assoreamento de rios, desmatamento, ocupação de áreas de preservação permanentes (APP), lançamento de esgotos diretamente nos rios, etc. Além de estimular as potencialidades presentes na região compreendida pela sub-bacia hidrográfica do rio Guamá como: ecoturismo, turismo planejado e rural, atividades agropecuárias, pesca artesanal, abastecimento de água, ações de educação ambiental, etc.. Por fim, a SBRG representa um lugar de beleza cênica e um patrimônio paisagístico riquíssimo de elevada biodiversidade.

AGRADECIMENTOS: a Superintendência do Desenvolvimento da Amazônia (SUDAM) pelo apoio financeiro ao projeto intitulado 'Desenvolvimento local integrado: a socioeconomia, proteção e reabilitação ambiental 
da microbacia do rio Guamá, Pará, Brasil'; a Universidade Federal Rural da Amazônia (UFRA), ao Instituto Socioambiental e dos Recursos Hídricos (ISARH) e ao Centro de Tecnologia Agropecuária (CTA).

\section{REFERÊNCIAS}

ABREU, E. M. A.; FERNANDES, A. R.; RUIVO, M. L. P.. Variação temporal e vertical de atributos químicos de um gleissolo do Rio Guamá cultivado com Canaranas. Revista Brasileira de Ciência do Solo, Viçosa, v.31, p.277-285, 2007. DOI: https://doi.org/10.1590/S0100-06832007000200010

ANA. Agência Nacional de Águas. Cuidando das águas: soluções para melhorar a qualidade dos recursos hídricos. Brasília: ANA, 2011.

ALMEIDA, R. F. B.; BAYER, M.; FERREIRA JÚNIOR, L. G.. Compartimentação morfométrica da Bacia do Rio Coco como subsídio a análise de fragilidade ambiental. Mercator, Fortaleza, v.15, n.4, p.83-94, 2016. DOI:

https://doi.org/10.4215/RM2016.1504.0006

AMANAJÁS, J. C.; BRAGA, C. C.. Padrões espaço-temporal pluviométricos na Amazônia Oriental utilizando análise multivariada. Revista Brasileira de Meteorologia, São José dos Campos, v.27, n.4, p.423-434, 2012. DOI: https://doi.org/10.1590/S0102-77862012000400006

ANDERSEN, L. J.; GOSK, J.. Applicability of vulnerability maps. Environmental Geology and Water Sciences, v.13, p.39-43, 1989. DOI: https://doi.org/10.1007/BF01666570

ARAÚJO, P. P.; OLIVEIRA, F. A.; CAVALCANTE, I. N.; QUEIROZ, J. C. B.; CARNEIRO, B. S.; TANCREDI, A. C. F. N. S..

Classificação hidroquímica e contaminação por nitrato no aquífero livre Barreiras na bacia do rio Capitão Pocinho região do médio rio Guamá na Amazônia oriental. Revista Ambiente \& Água, Taubaté, v.6, n.2, p.266-281, 2011. DOI: http://dx.doi.org/10.4136/ambi-agua.199

BARRETO, K. T.; PINTO, M. L. C.. Caracterização dos Indicadores Geomorfológicos na Bacia Hidrográfica do Rio Verde, Ponta Grossa/PR. Geografia, Ensino \& Pesquisa, Santa Maria, v.21, n.2, p.164-173, 2017. DOI: http://dx.doi.org/10.5902/2236499424088

BARROS, M. N. R.; ALMEIDA, A. S.; VIEIRA, I. C. G.. Análise especial da dinâmica do uso da terra e cobertura vegetal do Município de Mãe do Rio, Estado do Pará. In: ENCONTRO NACIONAL DA ANPPAS, 6. Anais. Belém: ANPPAS, 2012.

BATISTA, A. N. C.; ALMEIDA, N. V.; MELO, J. A. B.. Utilização de imagens CBERS no diagnóstico do uso e ocupação do solo na Microbacia do Riacho Maracajá, Olivedos, PB. Caminhos de Geografia, Uberlândia, v.10, n.32, p.235-244, 2009.

BELATO, L. S.; SERRÃO, S. L. C.. Aplicação da vulnerabilidade ambiental do município de Tomé-Açu, Estado do Pará. Revista Ibero-Americana de Ciências Ambientais, Aracaju, v.10, n.1, p.131-145, 2019. DOI: https://doi.org/10.6008/CBPC2179-6858.2019.001.0011

BELATO, L. S.; SERRÃO, S. L. C.; GANDRA, A. L. F.; AMORIM, I. L. S.. Aplicação da vulnerabilidade ambiental do município de Moju, estado do Pará. Revista Ibero-Americana de Ciências Ambientais, Aracaju, v.9, n.5, p.218-230, 2018. DOI:

\section{https://doi.org/10.6008/CBPC2179-6858.2018.005.0020}

BELTRAME, A. V.. Diagnóstico do meio ambiente físico de bacias hidrográficas: modelo de aplicação. Florianópolis: UFSC, 1994.

BRAUN, A. L.; AWRUCH, A. M.. Finite element simulation of the wind action over bridge sectional models: Application to the Guamá River Bridge (Pará State, Brazil). Finite Elements in Analysis and Design, Carolina do Norte, v.44, n.3, p.105122, 2018. DOI: https://doi.org/10.1016/j.finel.2007.11.006

BRASIL. Lei n. 12.651 de $\mathbf{2 5}$ de maio de 2012. Dispõe sobre a proteção da vegetação nativa; altera as Leis $n$ ㅇs 6.938 , de 31 de agosto de 1981, 9.393, de 19 de dezembro de 1996, e 11.428 , de 22 de dezembro de 2006; revoga as Leis $\mathrm{n}$-s 4.771, de 15 de setembro de 1965, e 7.754, de 14 de abril de 1989, e a Medida Provisória no 2.166-67, de 24 de agosto de 2001; e dá outras providências. Brasília: DOU, 2012.

BRASIL. Resolução n. $\mathbf{4 1 7}$ de $\mathbf{2 3}$ de novembro de 2009. Dispõe sobre parâmetros básicos para definição de vegetação primária e dos estágios sucessionais secundários da vegetação de Restinga na Mata Atlântica e dá outras providências. Brasília: DOU, 2009.

CELENTANO, D.; MIRANDA, M. V. C.; MENDONÇA, E. N.; ROUSSEAU, G. X.; MUNIZ, F. H.; LOCH, V. C.; VARGA, I. V. D.; FREITAS, L.; ARAÚJO, P.; NARVAES, I. S.; ADAMI, M.; GOMES, A. R.; RODRIGUES, J. C.; KAHWAGE, C.; PINHEIRO, M.; MARTINS, M. B.. Desmatamento, degradação e violência no 'Mosaico Gurupi' - A região mais ameaçada da Amazônia. Estudos Avançados, São Paulo, v.32, n.92, p.315-339, 2018. DOI: https://doi.org/10.5935/0103-4014.20180021

CHRISTOFOLETTI, A.. Geomorfologia. 2 ed. São Paulo: Edgard Blücher, 1980.

CORSEUIL, C. W.; CAMPOS, S.. Geoprocessamento aplicado na determinação das classes de declividade e uso de terras da microbacia do Arroio Ajuricaba - Marechal Cândido Rondom/PR. Energia na Agricultura, Botucatu, v.22, n.1, p.33-41, 2007.

COSTA, F. H. S.; PETTA, R. A.; LIMA, R. F. S.; MEDEIROS, C. N.. Determinação da vulnerabilidade ambiental na Bacia Potiguar, região de Macau (RN), utilizando sistemas de informações geográficas. Revista Brasileira de Cartografia, Uberlândia, v.58, n.2, p.119-127, 2006.

CREPANI, E.; MEDEIROS, J. S.; HERNANDEZ FILHO, P.; FLORENZANO, T. G.; DUARTE, V.; BARBOSA, C. C. F.. Sensoriamento remoto e geoprocessamento aplicados ao zoneamento ecológico-econômico e ao ordenamento territorial. São José dos Campos: INPE, 2001.

DUAN, Z.; LIU, J.; TUO, Y.; CHIOGNA, G.; DISSE, M.. Evaluation of eight high spatial resolution gridded precipitation products in Adige Basin (Italy) at multiple temporal and spatial scales. Science of the Total 
Environment, v.573, p.1536-1553, 2016. DOI: https://doi.org/10.1016/i.scitotenv.2016.08.213

CARNEIRO, R. S. G. S.; DUARTE, J. F. S.; RAMOS, A. J. R.. Análise de vulnerabilidade erosiva no município de Paragominas/PA. In: CONGRESSO BRASILEIRO DE CARTOGRAFIA, 27. Anais. Rio de Janeiro: SBC, 2017.

CONGALTON, R. G.; GREEN, K.. Assessing the accuracy of remotely sensed data: principles and practices. Flórida: CRC Press, 1999

ESPINOZA, J. C.; RONCHAIL, J.; MARENGO, J. A.; SEGURA, H. Contrasting North-South changes in Amazon wet-day and dry-day frequency and related atmospheric features (19812017). Climate Dynamics, v.52, p.5413-5430, 2019. DOI: https://doi.org/10.1007/s00382-018-4462-2

FAUVEL, M.; DECHESNE, C.; ZULLO, A.; FERRATY, F.. Fast forward feature selection of hyperspectral images for classification with gaussian mixture models. IEEE Journal of Selected Topics in Applied Earth Observations and Remote Sensing, v.8, n.6, p.2824- 2831, 2015. DOI: https://doi.org/10.1109/JSTARS.2015.2441771

FEITOSA, A.; FECHINE, J. A. L.; FERREIRA, C. W. S.; ARAÚJO, M. S. B.. Modelagem dinâmica de escoamento superficial influenciando a susceptibilidade à erosão dos solos num município do semiárido de Pernambuco. Revista Brasileira de Geomorfologia, Brasília, v.11, n.2, p.75-82, 2010. DOI: http://dx.doi.org/10.20502/rbg.v11i2.154

FIGUEIRÊDO, M. C. B.; VIEIRA, V. P. P. B.; MOTA, S.; ROSA, M. F.; MIRANDA, S.. Análise da vulnerabilidade ambiental. Fortaleza: Embrapa Agroindústria Tropical, 2010.

FIGUEROA, S. N; NOBRE, C. A.. Precipitations distribution over central and western tropical South American. Climanalise, São José dos Campos, v.5, n.6, p.36-45, 1990.

FISCH, G.; MARENGO, J. A.; NOBRE, C. A.. Uma revisão geral sobre o clima da Amazônia. Acta Amazônica, Manaus, v.28, n.2, p.101-126, 1998. DOI: https://doi.org/10.1590/180943921998282126

FRANCO, V. V.; SOUZA, J. O. P.. Análise morfométrica da bacia hidrográfica do riacho Jucurutu. Revista de Geociências do Nordeste, Caicó, v.2, p.252-261, 2016.

FREITAS, L. O.. Avaliação da Utilização de Imagens CBERS em Estudos de Uso e Cobertura do Solo. Monografia (Especialização em Geoprocessamento) - Universidade Federal de Minas Gerais, Belo Horizonte, 2010.

FREITAS, R. O. Textura de drenagem e sua aplicação geomorfológica. Boletim Paulista de Geografia, São Paulo, v.11, p.53-57, 1952.

FUJIMOTO, R. Y.; DIAS, H. M.; SOUSA, N. C.; COUTO, M. V. S.; SANTOS, R. F. B.; PAIXÃO, P. E. G.; CUNHA, F. S.; RAMOS, F. M.; SOUSA, K. N. S.; HOLANDA, F. C.. Is there sustainability for 'satellite' ornamental fishing regions? A case study of Guamá River basin/Pará, Brasil. Fisheries Research, Vancouver (Canadá), v.221, p.105354, 2020. DOI: https://doi.org/10.1016/i.fishres.2019.105354

FUNK, C.; PETERSON, P.; LANDSFELD, M.; PEDREROS, D.;
VERDIN, J.; SHUKLA, S.; HUSAK, G.; ROWLAND, J.; HARRISON, L.; HOELL, A.; MICHAELSEN, J.. The climate hazards infrared precipitation with stations: a new environmental record for monitoring extremes. Scientific Data, v.2, p.150066, 2015. DOI: https://doi.org/10.1038/sdata.2015.66

GERBER, D.; PERTILLE, C. T.; VIEIRA, F. S.; CORRÊA, B. J. S.; SOUZA, C. F.. Caracterização morfométrica da Bacia Hidrográfica do Rio Itajaí - Santa Catarina. Acta Biológica Catarinense, Santa Catarina, v.5, n.1, p.72-83, 2018. DOI: http://dx.doi.org/10.21726/abc.v5i1.446

GRIMM, A. M.. Interannual climate variability in South America: impacts on seasonal precipitation, extreme events, and possible effects of climate change. Stochastic Environmental Research and Risk Assessment, v.25, n.4, p.537-554, 2011. DOI: https://doi.org/10.1007/s00477-0100420-1

GUTIERREZ, C. B. B.; RIBEIRO, H. M. C.; MORALES, G. P.; GUTIERREZ, D. M. G.; SANTOS, L. S.; PAULA, M. T.. Análise espaço-temporal do uso e cobertura do solo no interior da APA Belém e correlação com os parâmetros de água dos seus mananciais. Revista Brasileira de Geografia Física, Recife, v.10, n.1, p.521-534, 2017. DOI: https://doi.org/10.5935/1984-2295.20170033

HORTON, R. E.. Erosional development of streams and their drainage basins: hydrophysical approach to quantitative morphology. Geological Society of America Bulletin, v.56, n.3, p.275-370, 1945. DOI: https://doi.org/10.1130/00167606(1945)56[275:EDOSAT]2.0.CO;2

HUDSON, W. D.; RAMM, C. W.. Correct formulation of the Kappa coefficient of agreement. Photogrammetric Engineering and Remote Sensing, v.53, n.54, p.421-422, 1987. DOI: https://doi.org/0099-1112/87/5304-421502.25/0

IBGE. Instituto Brasileiro de Geografia e Estatística.

Mudanças na cobertura e uso da terra. Rio de Janeiro: IBGE, 2016.

IDESP. Instituto de Desenvolvimento Econômico, Social e Ambiental do Pará. Estatística Municipal: Capitão Poço. Belém: Governo do Estado do Pará, 2014.

JIMÉNEZ, K. Q.; MELO, T. M.; LOUZADA, J. A.. Uso de dados de precipitação obtidos por sensoriamento remoto em um modelo agro-hidrológico. Irriga, São Paulo, v.18, n.3, p.496 508, 2013. DOI: https://doi.org/10.15809/irriga.2013v18n3p496

KLAIS, T. B. A.; DALMAS, F. B.; MORAIS, R. P.; ATIQUE, G.; LASTORIA, G.; PARANHOS FILHO, A. C.. Vulnerabilidade natural e ambiental do município de Ponta Porã, Mato Grosso do Sul, Brasil. Revista Ambiente \& Água, Taubaté, v.7, n.12, p.277-290, 2012. DOI: http://dx.doi.org/10.4136/ambi-agua.786

LANDIS, J. R.; KOCH, G. G.. The Measurement of Observer Agreement for Categorical. Biometrics, v.33, p.159-174, 1977. DOI: https://doi.org/10.2307/2529310

LEITE, E. F.; ROSA, R.. Determinação e caracterização de unidades de paisagem natural na Bacia Hidrográfica do Rio Formiga-TO a partir de técnicas de geoprocessamento. In: SIMPÓSIO BRASILEIRO DE SENSORIAMENTO REMOTO, 16. 
Anais. Foz do Iguaçu: INPE, 2013.

LIMA, W. P.. Princípios de manejo de bacias hidrográficas. Piracicaba: USP, 1976.

LOLLO, J. A.. O uso da técnica de avaliação do terreno no processo de elaboração do mapeamento geotécnico: sistematização e aplicação na quadrícula de Campinas. Tese (Doutorado em Geotecnia) - Universidade de São Paulo, São Paulo, 1995.

LOPES, F. B.; BARBOSA, C. C. F.; NOVO, E. M. L. M.; ANDRADE, E. M.; CHAVES, L. C. G.. Modelagem da qualidade das águas a partir de sensoriamento remoto hiperespectral. Revista Brasileira de Engenharia Agrícola e Ambiental, Campina Grande, v.18, p.S13-S19, 2014. DOI: https://doi.org/10.1590/1807-1929/agriambi.v18nsupps13$\underline{\mathrm{s} 19}$

MACHADO, C. J. S.. Gestão de águas Doces. Rio de Janeiro: Interciência, 2004.

MACHADO, R. A. S.; LOBÃO, J. S. B.; VALE, R. M. C.; SOUZA, A. P. M. J.. Análise morfométrica de bacias hidrográficas como suporte à definição e elaboração de indicadores para a gestão ambiental a partir do uso de geotecnologias. In: ANAIS DO SIMPÓSIO BRASILEIRO DE SENSORIAMENTO REMOTO, 15. Anais. Curitiba: SBSR, 2011.

MANZANO, M. N.; FERREIRA, A. T. S.; SAAD, A. R.; PIZZATO, E.; QUEIROZ, W.; DALMAS, F. B.. Fragilidade a inundações da Bacia Hidrográfica do Rio Baquirivu-Guaçu (Guarulhos, SP). Pesquisas em Geociências, Porto Alegre, v.46, n.3, p.e0785, 2019. DOI: https://doi.org/10.22456/1807-9806.97383

MARCIANO, A. G.; BARBOSA, A. A.; SILVA, A. P. M.. Cálculo de precipitação média utilizando método de Thiessen e as linhas de cumeada. Revista Ambiente \& Água, Taubaté, v.13, n.1, p.e1906, 2018. DOI: https://doi.org/10.4136/ambiagua.1906

MELO, M. F. C.; SANTOS, J. N.; SANTOS, C. P.. Sciadicleithrum juruparii n. sp. (Monogenea: Ancyrocephalidae) from the gills of Satanoperca jurupari (Heckel) (Osteichthyes: Cichlidae) in the Guamá River, Amazon Delta, Brazil. Systematic Parasitology, v.82, p.125-129, 2012. DOI: https://doi.org/10.1007/s11230-012-9353-z

MENDES, A. T.. Delimitação da bacia hidrográfica do Rio Santo Antônio pela ferramenta de delimitação automática TauDEM. Revista Brasileira de Geografia Física, Recife, v.11, n.03, p.973-986, 2018. DOI:

https://doi.org/10.26848/rbgf.v11.3.p973-987

MILANEZI, C. H. S.; PEREIRA, J. G.. Caracterização da vulnerabilidade ambiental na Microbacia do Córrego Azul, Ivinhema/MS. Geografia, Londrina, v.25, n.1, p.43-63, 2016. DOI: http://dx.doi.org/10.5433/2447-1747.2016v25n1p43

MIOTO, C. L.; OLIVEIRA, R. V.; QUEIROZ, S. D. M.; PEREIRA, T. V.; ANACHE, J. A. A.; PARANHOS, F. A. C.. Morfometria de bacias hidrográficas através de SIGs livres e gratuitos. Anuário do Instituto de Geociências, Rio de Janeiro, v.37, n.2, p.16-22, 2017. DOI:

http://dx.doi.org/10.11137/2014 21622

MORAES, M. E. B.; LORANDI, R.. Métodos e técnicas de pesquisas em bacias hidrográficas. Ilhéus: Editus, 2016.

MOREIRA, T. R.; SANTOS, A. R.; DALFI, R. L.; CAMPOS, R. F.; SANTOS, G. M. A. D. A.; EUGENIO, F. C.. Confronto do uso e ocupação da terra em APPs no Município de Muqui, ES. Floresta e Ambiente, Rio de Janeiro, v.22, n.2, p.141-152, 2015. DOI: https://doi.org/10.1590/2179-8087.019012

NEVES, L. V.; DEUS, L. A. B.; OSCAR JUNIOR, A. C. S.; FERNANDES, M. C.. Mudanças de Uso e Cobertura da Terra e Áreas Suscetíveis à Inundação: Estudo de Caso do Município de Duque de Caxias/RJ. Revista do Departamento de Geografia, São Paulo, v.37, 2019. DOI: https://doi.org/10.11606/rdg.v37i0.149051

NIMER, E.. Climatologia do Brasil. 2 ed. Rio de Janeiro: IBGE, 1989.

PINTO JUNIOR, O. B.; ROSSETE, A. N.. Caracterização morfométrica da bacia hidrográfica do Ribeirão Cachoeira, MT-Brasil. Revista Eletrônica Geoambiente, n.4, p.1-16, 2005. DOI:

https://doi.org/10.5216/rev.\%20geoambie.v0i4.25872

PONTE, F. C.; FURTADO, A. M. M.; SILVA, C. N.; SILVA, J. M. P.; LIMA, R. S.. Parâmetros fisiográficos e impactos ambientais da rodovia Santarém-Cuiabá (BR-163), Estado do Pará, Brasil. Revista Eletrônica do PRODEMA, Fortaleza, v.9, n.2, p.53-64, 2016

PORTO, M. L.; JESUS, E. S.; PEREIRA JUNIOR, A.. Análise das tendências nas relações entre fluxo de veículos, arborização e os níveis de intensidade de ruído. Ecologia e Nutrição Florestal, Santa Maria, v.5, n.3, p.87-97, 2017. DOI: http://dx.doi.org/10.5902/2316980X27773

ROCHA, N. C. V.; LIMA, A. M. M.. A sustentabilidade hídrica na bacia do rio Guamá, Amazônia Oriental/Brasil. Sociedade \& Natureza, Uberlândia, v.32, p.141-160, 2020. DOI: https://doi.org/10.14393/SN-v32-2020-45694

RODRIGUES, C. C. S.; SANTOS, E.; RAMOS, B. S. DAMASCENO, F. C.; CORREA, J. A. M.. PAH Baselines for Amazonic Surficial Sediments: A Case of Study in Guajará Bay and Guamá River (Northern Brazil). Bulletin of Environmental Contamination and Toxicology, v.100, p.786791, 2018. DOI: https://doi.org/10.1007/s00128-018-2343-3

ROMERO, F. I.; COZANO, M. A.; GANGAS, R. A.; NAULIM, P. I.. Zonas ribereñas: protección, restauración y contexto legal en Chile. Bosque, Valdivia (Chile), v.35, n.1, p.3-12.

2014.DOI: http://dx.doi.org/10.4067/S0717$\underline{92002014000100001}$

SANTOS, A. F.. Lançamento do CBERS-4: Sucesso Total. Revista Brasileira de Direito Aeronáutico e Espacial, Rio de Janeiro, n.96, p.5-8, 2014.

SANTOS, A. M.; TARGA, M. S.; BATISTA, G. T.; DIAS, N. W. Análise morfométrica das sub-bacias hidrográficas Perdizes e Fojo no município de Campos do Jordão, SP, Brasil. Ambiente \& Água, Taubaté, v.7, n.3, p.195-211, 2012. DOI: http://dx.doi.org/10.4136/ambi-agua.945

SANTOS, G. R.; COELHO, A. S.. Bacia hidrográfica e a confecção de recursos didáticos por alunos do ensino fundamental em Sergipe. Geografia, Ensino \& Pesquisa, 
Santa Maria, v.24, p.e12, 2020. DOI:

http://dx.doi.org/10.5902/2236499436065

SANTOS, S. O.; CARNEIRO, A. S.; LOBÃO, J. S. B.. Análise de parâmetros morfométricos aplicados para a caracterização de uma bacia hidrográfica. In: ANAIS DO SIMPÓSIO REGIONAL DE GEOPROCESSAMENTO E SENSORIAMENTO REMOTO, 8. Anais. Salvador: GEONORDESTE, 2017.

SCHUMM, S. A.. Evolution of drainage systems and slopes in badlands at Perth Amboy, New Jersey. Geological Society of America Bulletin, v.67, n.5, p.597-646, 1956. DOI: https://doi.org/10.1130/00167606(1956)67[597:EODSAS]2.0.CO;2

SILVA, C. B.; SILVA, M. E. S.; AMBRIZZI, T.; TOMMASELLI, J. T. G.; PATUCCI, N. N.; MATAVELI, G. A. V.; LIMA, B. S.; CORREA W. C.. Precipitação na América do Sul: dados obtidos em estações meteorológicas automáticas e sistemas orbitais. Revista Brasileira de Climatologia, Paraná, v.25, p.54-79, 2019. DOI: http://dx.doi.org/10.5380/abclima.v25i0.58813

SILVA, G. C.; ALMEIDA, F. P.; ALMEIDA, R. T. S.; MESQUITA, M.; ALVES JUNIOR, J.. Caracterização morfométrica da bacia hidrográfica do Riacho Rangel-Piauí, Brasil. Enciclopédia Biosfera, Goiânia, v.15, n.28, p.244-258, 2018.

SILVA, J. S.; SILVA, R. M.; SILVA, A. M.. Mudanças do uso e ocupação do solo e degradação eco-ambiental usando imagens orbitais: o estudo de caso da bacia do Rio Bacanga, São Luís (MA). Revista Brasileira de Geografia Física, Recife, v.9, n.1, p.265-27, 2016. DOI:

https://doi.org/10.26848/rbgf.v9.1.p265-279

SILVA, L. G. T.; SILVA, B. N. R.; RODRIGUES, T. E.. Análise fisiográfica das várzeas do baixo Tocantins: uma contribuição ao manejo e desenvolvimento dos sistemas de uso da terra. Belém: Embrapa Amazônia Oriental, 2002.

SILVA, R. S.; BARBOSA, C. O.; MONTEIRO, F. G.; CORREA, D. L.; GOMES, A. S.. Análise multitemporal de parte da Reserva do Alto Rio Guamá, Paragominas, PA. Pesquisa Florestal Brasileira, Paraná, v.39, p.1-10, 2019. DOI: https://doi.org/10.4336/ 2019.pfb.39e201801712

SILVEIRA, A. L. L.. Desempenho de Fórmulas de Tempo de Concentração em Bacias Urbanas e Rurais. Revista Brasileira de Recursos Hídricos, Bento Gonçalves, v.10, n.01, p.05-23, 2005. DOI: https://doi.org/10.21168/rbrh.v10n1.p5-29
SOUZA, B. F.; KOTSUBO, K.; FRACACIO, G.; TREVISAN, D. T.; CASSIANO, A. M.; MOSCHINI, L. E.; CATOJO, A. M. Z. Avaliação da qualidade dos corpos hídricos frente ás ações antrópicas no município de Santa Lúcia/SP. Revista Brasileira de Geografia Física, Recife, v.10, n.1, p.317-331, 2017. DOI: https://doi.org/10.5935/1984-2295.20170019

SOUZA, E. B.; AMBRIZZI, T.. Pentad precipitation climatology over Brazil and the associated atmospheric mechanisms. Climanálise, São José dos Campos, v.5, n.6, p.36-44, 2003.

STIPP, N. A. F.; CAMPOS, R. A; CAVIGLIONE, J. H.. Análise morfométrica da bacia hidrográfica do rio Taquara: uma contribuição para o estudo das Ciências Ambientais. Portal da Cartografia, Paraná, v.3, n.1, p.105-124, 2010.

STRAHLER, A. N.. Hypsometric (area-altitude) analysis of erosional topography. Geological Society of America Bulletin, v.63, n.11, p.1117-1142, 1952. DOI: https://doi.org/10.1130/00167606(1952)63[1117:HAAOET]2.0.CO;2

SUMMERFIELD, M. A.. Global Geomorphology: an introduction of the study of landforms. Harlow: Essex, Longman Scientific \& Technical, 1991.

TAGLIANI, C. R.. Técnica para avaliação da vulnerabilidade ambiental de ambientes costeiros utilizando um sistema geográfico de informações. In: SIMPÓSIO BRASILEIRO DE SENSORIAMENTO REMOTO, 11. Anais. Belo Horizonte: INPE, 2003.

TONELLO, K. C.. Análise hidroambiental da bacia hidrográfica da cachoeira das Pombas, Guanhães, MG. Tese (Doutorado em Ciências Florestal) - Universidade Federal de Viçosa, Viçosa, 2005.

TRICART, J.. Ecodinâmica. Rio de Janeiro: IBGE-SUPREN, 1977.

VILLELA, S. M.; MATTOS, A.. Hidrologia aplicada. São Paulo: Mc Graw-Hill do Brasil, 1975.

VILELA FILHO, L. R.; VITTE, A. C.. A utilização de técnicas morfométricas do relevo aplicadas na determinação da fragilidade ambiental: o caso da bacia do córrego Proença, município de Campinas (SP). In: ENCONTRO DE GEÓGRAFOS DA AMÉRICA LATINA, 10. Anais. São Paulo: USP, 2005.

A CBPC - Companhia Brasileira de Produção Científica (CNPJ: 11.221.422/0001-03) detém os direitos materiais desta publicação. Os direitos referem-se à publicação do trabalho em qualquer parte do mundo, incluindo os direitos às renovações, expansões e disseminações da contribuiç̃o, bem como outros direitos subsidiários. Todos os trabalhos publicados eletronicamente poderão posteriormente ser publicados em coletâneas impressas sob coordenação da Sustenere Publishing, da Companhia Brasileira de Produção Científica e seus parceiros autorizados. Os (as) autores (as) preservam os direitos autorais, mas não têm permissão para a publicação da contribuição em outro meio, impresso ou digital, em português ou em tradução. 